OLIVER, Guillermo. "Aproximación a la unificación de penas".

Polít. crim. Vol. 7, No 14 (Diciembre 2012), Art. 1, pp. 248 - 275.

[http://www.politicacriminal.cl/Vol_07/n_14/Vol7N14A1.pdf]

\title{
Aproximación a la unificación de penas*
}

\author{
Guillermo Oliver Calderón \\ Doctor en Derecho por la Universidad de Barcelona \\ Profesor de Derecho Penal y Derecho Procesal Penal \\ Pontificia Universidad Católica de Valparaíso \\ guillermo.oliver@ucv.cl
}

\section{Resumen}

En el presente trabajo se analiza la regla de determinación de la pena contemplada en el artículo 164 del Código Orgánico de Tribunales. Se examinan los cambios que en su configuración supuso la reforma procesal penal, sus requisitos de procedencia y algunos aspectos procesales envueltos en su aplicación.

\section{Palabras clave}

Unificación de penas, determinación de la pena, individualización de la pena

\begin{abstract}
The following article analyzles the rule for determining the sanction in Article 164 of the Organic Code of Courts. The changes in its configuration brought by the penal procedural reform are examined, as well as its application requirements and some procedural aspects related to its execution.
\end{abstract}

\section{Key words}

Unification of penalties, determination of sanction, individualization of the sanction.

\section{Introducción.}

Se conoce con el nombre "unificación de penas" la regulación que se contiene en el artículo 164 del Código Orgánico de Tribunales. Según su primer inciso,

\footnotetext{
" Este trabajo se ha realizado dentro del marco del proyecto de investigación Fondecyt $N^{\circ} 1100901$, "El proceso de determinación de la pena: estudio dogmático y crítico", en el que el autor se desempeña como investigador responsable. El autor agradece a don José Manuel Sánchez Piazza, ayudante del Departamento de Derecho Penal y Derecho Procesal Penal de la Pontificia Universidad Católica de Valparaíso, por su colaboración en la revisión de aspectos formales de este trabajo y por sus observaciones destinadas a mejorarlo.
} 
OLIVER, Guillermo. "Aproximación a la unificación de penas".

"cuando se dictaren distintas sentencias condenatorias en contra de un mismo imputado, los tribunales que dictaren los fallos posteriores al primero no podrán considerar circunstancias modificatorias que de haberse acumulado los procesos no se hubieren podido tomar en cuenta. Deberán, asimismo, regular la pena de modo tal que el conjunto de penas no pueda exceder de aquella que hubiere correspondido de haberse juzgado conjuntamente los delitos".

Agrega el siguiente y último inciso de la citada disposición, que

"en los casos del inciso anterior, el tribunal que dictare el fallo posterior deberá modificarlo, de oficio o a petición del afectado, a objeto de adecuarlo a lo allí dispuesto".

La mocedad de este precepto, su compleja redacción, el escaso interés (aunque paulatinamente creciente) que ha mostrado en él la doctrina nacional ${ }^{1}$-probablemente debido a su ubicación extramuros del Código Penal y del Código Procesal Penal-, siguiendo lo que parece ser una tendencia en el ámbito de la determinación de la pena, y la contradictoria y a veces poco fundada jurisprudencia que se ha pronunciado sobre aquél, han originado en la práctica varios problemas de interpretación y aplicación que demandan propuestas de solución. En este trabajo, se intenta resolver algunos de esos problemas, para lo cual es imprescindible precisar previamente el origen y el fundamento de la figura.

\section{Antecedentes.}

El tenor actual del artículo 164 del Código Orgánico de Tribunales fue fijado por la Ley $\mathrm{N}^{\mathrm{o}}$ 19.665, de 9 de marzo de 2000, que modificó dicho cuerpo normativo para adaptarlo a la estructura y principios del nuevo proceso penal. Su antecedente fue el artículo 160 del mismo Código, ${ }^{2}$ que era aplicable en el antiguo sistema de enjuiciamiento criminal y cuyo tenor era el siguiente:

"El culpable de diversos delitos será juzgado por todos ellos en un solo proceso, para lo cual se acumularán las causas iniciadas o por iniciarse en su contra; y las personas que en ellas figuren como reos quedarán sometidas a la jurisdicción del tribunal a quien corresponda conocer en los procesos acumulados" (inciso primero).

En su inciso segundo esta disposición agregaba que

"sin perjuicio de la regla anterior, el juez podrá ordenar por medio de un auto motivado la desacumulación de los procesos o su sustanciación por cuerda separada, cuando éstos tengan una tramitación diferente o plazos especiales para su tramitación, o la acumulación determine un grave retardo en la sustanciación de las causas. Los

\footnotetext{
${ }^{1}$ Los manuales nacionales de parte general del derecho penal prácticamente no destinan ninguna línea al tratamiento de esta figura.

${ }^{2}$ Véase un comentario de este último precepto en VAN WEEZEL, Alex, "Unificación de las penas: la regla del artículo 160 inciso $2^{\circ}$ del Código Orgánico de Tribunales", Revista de Derecho de la Universidad de Concepción $\mathrm{n}^{\circ}$ 207, año LXVIII (2000), pp. 55-58.
} 
procesos separados seguirán tramitándose ante el mismo juez a quien correspondía conocer de ellos acumulados y al fallarlos deberá considerar las sentencias que hayan sido dictadas con anterioridad en estos procesos. Si procediere unificar las penas, el tribunal lo hará al dictar la última sentencia. Con todo, este último fallo no tomará en consideración las sentencias anteriores para apreciar las circunstancias modificatorias de responsabilidad penal".

Este artículo, que finalizaba con un tercer inciso cuyo examen no resulta pertinente para este trabajo, fue derogado por la Ley $\mathrm{N}^{\circ} 19.708$, de 5 de enero de 2001.

Una disposición parecida al antiguo artículo 160 del Código Orgánico de Tribunales se encuentra aún vigente en el artículo 12 del Código de Justicia Militar, que reza así:

"Cuando se hubiere cometido por un mismo agente delitos de jurisdicción militar y de jurisdicción común, que no sean conexos, el Tribunal Militar será competente para conocer de los primeros y el tribunal ordinario de los segundos. Si la aplicación de esta norma creare alguna interferencia o dificultad para la práctica de medidas o diligencias que se relacionan con el inculpado, tendrán preferencia las requeridas por el Tribunal Militar" (inciso primero). "Los Tribunales deberán remitirse recíprocamente copias de los autos de procesamiento y de los fallos que se dictaren en sus respectivas causas, las que deberán agregarse a los autos" (inciso segundo). "El tribunal que dictare el último fallo no podrá considerar circunstancias modificatorias de responsabilidad criminal que de estar acumulados los procesos no se hubieren podido tomar en cuenta" (inciso tercero). "El condenado podrá solicitar dentro del plazo de un año a contar del último fallo, al tribunal superior común, la unificación de las penas cuando ello lo beneficiare" (inciso cuarto).

Preceptos semejantes han formado parte de la regulación de los delitos de tráfico de drogas. Así, por ejemplo, el artículo 22 de la Ley $\mathrm{N}^{\circ} 18.403$, de 4 de marzo de 1985, disponía lo siguiente:

"Si se investigaren delitos previstos en esta ley y en otras leyes penales, cometidos por el mismo hechor y que no sean conexos, los procesos se tramitarán por cuerda separada, ante el Tribunal que corresponda" (inciso primero). "Asimismo, no procederá la acumulación de autos entre procesos que conozcan diversos Tribunales por delitos contemplados en la presente ley, a menos que por causa justificada y debidamente calificada, se dispusiere por el Tribunal superior común la acumulación de tales procesos ante el Tribunal que estime procedente" (inciso segundo). "Si la aplicación de las normas señaladas en los incisos precedentes creare retardo o dificultades en la práctica de medidas o diligencias que se relacionen con el inculpado, tendrán preferencia las requeridas por el Tribunal que conozca los delitos previstos en esta ley, sin perjuicio de lo dispuesto en el artículo 12, inciso primero, del Código de Justicia Militar" (inciso tercero). "Los tribunales deberán remitirse recíprocamente copias de los autos de procesamiento y de los fallos que se dictaren en sus respectivas causas, las que deberán agregarse a los autos" (inciso cuarto). "El Tribunal que dictare el último fallo no podrá considerar aquellas circunstancias modificatorias de responsabilidad criminal que, de estar acumulados los procesos, no se hubieren podido tomar en cuenta" (inciso quinto). "El reo podrá solicitar al 
OLIVER, Guillermo. “Aproximación a la unificación de penas”.

Tribunal superior común dentro del plazo de un año contado desde la dictación del último fallo, la unificación de las penas cuando ello lo beneficiare" (inciso sexto).

Una disposición muy similar se encontraba en el artículo 38 de la Ley $\mathrm{N}^{\circ} 19.366$, de 18 de octubre de 1995, la que ampliaba a dos años el plazo para solicitar al tribunal superior común la unificación de las penas. ${ }^{3}$ En cambio, la actual ley de drogas, la Ley $\mathrm{N}^{\circ} 20.000$, de 16 de febrero de 2005, no contiene ningún precepto parecido.

\section{Fundamento.}

El propósito de la regulación que se contenía en el antiguo artículo 160 del Código Orgánico de Tribunales y el de la que se prevé en el actual artículo 164 del mismo Código, parecen ser similares. Lo que se pretende es evitar que cuando exista una pluralidad de procesos que se sigan en contra de una misma persona, por distintos hechos que pudieron ser juzgados conjuntamente, la suma de las condenas impuestas en cada uno de ellos produzca una situación más gravosa para el imputado, al resultar superior, por su naturaleza o su cuantía, a las penas que habría correspondido imponer si se hubiera efectuado un juzgamiento conjunto.

El presupuesto básico de las figuras parece ser, entonces, la existencia de un concurso de delitos. ${ }^{4}$ Como es sabido, el artículo 74 del Código Penal consagra en materia concursal un sistema de acumulación aritmética o material de penas, el cual se caracteriza por el hecho de que cuando un sujeto ha cometido varios delitos, se le deben imponer las sanciones asignadas a cada uno de ellos. A este sistema se oponen el de absorción, que se traduce en aplicar sólo la pena correspondiente al delito de mayor gravedad, y el de acumulación jurídica o asperación, en cuya virtud "las penas de varios delitos deben ser mayores que la de uno solo y ser aumentadas en relación al número y entidad de los diversos delitos cometidos, pero sin llegar a la suma aritmética. Generalmente se toma la pena correspondiente al más grave de los delitos perpetrados por el sujeto y se le aumenta prudencialmente, según el número e importancia de los demás". 5

A pesar de que el Código Penal chileno no adopta ninguno de estos sistemas de manera exclusiva, la doctrina nacional afirma que lo dispuesto en el artículo 74 constituye la regla general en materia de concurso de delitos. Las excepciones (principales) están constituidas por las reglas de punición de la reiteración de delitos de la misma especie (arts. 351 y 397 CPP), las cuales establecen un sistema de acumulación jurídica, y las reglas sobre reiteración de hurtos (art. $451 \mathrm{CP}$ ) y sobre concursos ideal y medial de delitos (art. $75 \mathrm{CP}$ ),

\footnotetext{
${ }^{3}$ Sendos comentarios sobre esta última disposición pueden leerse en DÍAZ CRUZAT, Andrés, "Esquema sobre la unificación de penas de la Ley No 19.366", Gaceta Jurídica n ${ }^{\circ} 236$ (2000), pp. 147-152, y en EL MISMO, "Problemas anexos a la unificación de penas", Gaceta Jurídica n 245 (2000), pp. 7-9.

${ }^{4}$ En este sentido, por lo que respecta al antiguo artículo 160 del Código Orgánico de Tribunales, VAN WEEZEL, "Unificación de las penas", cit. nota n² 2, p. 56. En relación con el actual artículo 164 de dicho Código, véase MATUS ACUÑA, Jean Pierre, "Proposiciones respecto de las cuestiones no resueltas por la Ley $\mathrm{N}^{\circ} 20.084$ en materia de acumulación y orden de cumplimiento de las penas", Ius et Praxis $\mathrm{n}^{\circ} 2$, año 14 (2008), pp. 525-559, pp. 540 y ss.

${ }^{5}$ NOVOA MONREAL, Eduardo, Curso de Derecho Penal Chileno, t. II, $3^{a}$ ed., Santiago: Editorial Jurídica de Chile, 2005, p. 226.
} 
Polít. crim. Vol. 7, No 14 (Diciembre 2012), Art. 1, pp. 248 - 275.

[http://www.politicacriminal.cl/Vol_07/n_14/Vol7N14A1.pdf]

que consagran un sistema de absorción agravada, ${ }^{6}$ sin perjuicio de otras reglas especiales establecidas para determinar las penas aplicables en concursos de ciertos delitos, como sucede en la regulación del cohecho (art. 249 inc. $2^{\circ} \mathrm{CP}$ ) y de la receptación (art. 456 bis A inc. $\left.4^{\circ} \mathrm{CP}\right)$.

Las mencionadas excepciones se han introducido en nuestro ordenamiento como una forma de atenuar los efectos eventualmente perniciosos de la aplicación ortodoxa de la regla del artículo 74 del Código Penal. La doctrina suele destacar que los sistemas alternativos a la acumulación material o aritmética humanizan la sanción, pues evitan la imposición de penas desproporcionadas que sobrepasan, a veces, el tiempo de vida del delincuente. ${ }^{7}$ El Código Penal chileno sólo estableció como excepciones a la regla de la acumulación material, las relativas a la reiteración de hurtos y a los concursos ideal y medial de delitos, lo que generó en sus primeros años de vigencia diversas críticas doctrinales, por la cuantía excesiva de las penas que a veces se imponían en aplicación de la primera de aquellas reglas. ${ }^{8}$ Fue recién en 1907, con la entrada en vigencia del Código de Procedimiento Penal, cuando se introdujo la regla de punición de la reiteración de delitos de la misma especie (fue el artículo 537, que después pasó a ser el artículo 509) ${ }^{9}$ actualmente recogida en el Código Procesal Penal, aunque con modificaciones-, con lo cual se limitó en mayor medida la aplicación del artículo 74 del Código Penal.

En todo caso, vale la pena tener presente que nuestro ordenamiento jurídico penal nunca ha contemplado disposiciones que establezcan límites máximos a la duración de las penas privativas de libertad. ${ }^{10}$ En los sistemas que prevén normas de esta clase, como lo hace, por ejemplo, el Código Penal español de 1995 (art. 76), la regla de la acumulación aritmética sufre una doble morigeración: por un lado, a través de las reglas concursales que establecen sistemas de penalidad alternativos, y por otro, mediante la limitación máxima de la duración de las penas privativas de libertad que pueden imponerse al condenado. ${ }^{11}$

\footnotetext{
${ }^{6}$ POLITOFF LIFSCHITZ, Sergio; MATUS ACUÑA, Jean Pierre; RAMÍREZ GUZMÁN, María Cecilia, Lecciones de derecho penal chileno: Parte general, $2^{a}$ ed., Santiago: Editorial Jurídica de Chile, 2004, p. 466.

${ }^{7}$ NOVOA MONREAL, Curso, cit. nota $\mathrm{n}^{\circ}$ 5, p. 222. En el mismo sentido, GARRIDO MONTT, Mario, Derecho Penal: Parte general, t. II, $2^{a}$ ed., Santiago: Editorial Jurídica de Chile, 2001, p. 345.

${ }^{8}$ Véase CORREA BRAVO, Agustín, "Ochenta y cuatro años de presidio", Revista Forense Chilena, t. IV (1888), pp. 508-511; FELIÚ, Daniel, "De la acumulación de los delitos según nuestro Código Penal”, Revista Forense Chilena, t. VI (1890), pp. 436-444; LATORRE, Enrique et al, "Ciento veintitrés años cuarenta y un días de presidio", Revista Forense Chilena, t. XIII (1899), pp. 399-402.

${ }^{9}$ SOLARI PERALTA, Tito; RODRÍGUEZ COLLAO, Luis. "Determinación de la pena en los casos de reiteración de delitos (Ámbito de aplicación del Artículo 509 del Código de Procedimiento Penal)", Revista de Derecho, Pontificia Universidad Católica de Valparaíso, vol. III (1979), pp. 255- 271, p. 258.

${ }_{10}$ Ello, con la notable excepción del artículo 18 de la Ley $\mathrm{N}^{\mathrm{o}} 20.084$ sobre responsabilidad penal de adolescentes, aun cuando parece evidente que el fundamento de esta disposición se halla más bien en la especial consideración de las características del adolescente, como persona que se encuentra en proceso de desarrollo.

${ }^{11}$ También se encuentran límites máximos a la duración de las penas privativas de libertad que se impongan, en los Códigos Penales argentino (art. 55), brasileño (art. 75), colombiano (arts. 31 y 37) costarricense (art. 51), hondureño (art. 35), panameño (art. 52) y peruano (art. 50), entre otros.
} 
OLIVER, Guillermo. “Aproximación a la unificación de penas”.

El antiguo artículo 160 y el actual artículo 164 del Código Orgánico de Tribunales se sitúan dentro de este contexto. Ambas disposiciones buscan evitar que, a raíz de una decisión de índole procesal que se traduzca en el juzgamiento separado de hechos que podrían juzgarse conjuntamente, se perjudique al imputado y se le impongan penas más severas, por no poder aplicarse las reglas concursales que constituyen una excepción al artículo 74 del Código Penal, por no poder apreciarse atenuantes (como la irreprochable conducta anterior o la reparación del daño causado) o por tener que considerarse agravantes (como la reincidencia).

No obstante, que el presupuesto de aplicación del citado artículo 164 parezca ser un concurso de delitos, no impide utilizar esta disposición en otras hipótesis que también suponen la realización de varios hechos pero que pueden ser valorados como uno solo, como ocurre, por ejemplo, en el caso del delito continuado, siempre que concurran sus requisitos. ${ }^{12}$ Téngase presente que en el origen histórico de la figura del delito continuado, también influyeron consideraciones penológicas que giraron en torno a la idea de evitar la aplicación de sanciones excesivamente severas. ${ }^{13}$

En el procedimiento penal anterior al actual, de acuerdo con lo que establecía el primer inciso del antiguo artículo 160 del Código Orgánico de Tribunales, la regla general era la de la acumulación de los procesos. Por lo tanto, lo usual era que el inculpado de varios delitos fuera juzgado por todos ellos en un mismo proceso que finalizara con una única sentencia, la que imponía las penas conforme al sistema de acumulación aritmética o a alguno de los sistemas de absorción o de acumulación jurídica, según correspondiera.

Excepcionalmente, conforme al segundo inciso del citado precepto, tenía lugar la desacumulación de los procesos (en las hipótesis de tramitación diferente, plazos especiales o grave retardo en la sustanciación de las causas), en cuyo caso el juez del crimen debía tramitar cada causa en forma separada. Pero al dictar la última sentencia condenatoria debía unificar las penas, es decir, considerar los delitos como si se hubiesen juzgado en un solo proceso y se hubiese dictado a su respecto un solo fallo, y aplicar a todos ellos la regla de punición del concurso de delitos que fuera pertinente, siempre que ello resultara más favorable para el reo. Además, debía prescindir de las sentencias anteriores para apreciar las circunstancias modificatorias de responsabilidad penal. ${ }^{14}$

La reforma del sistema procesal penal supuso un cambio radical en los presupuestos de aplicación de la figura examinada, ya que desapareció la acumulación obligatoria de procesos seguidos contra un mismo inculpado (y su excepcional desacumulación), como una facultad del órgano jurisdiccional, para dar lugar a una prerrogativa del Ministerio

\footnotetext{
${ }^{12}$ Así, MORALES ESPINOZA, Eduardo, "La regulación de la pena en conformidad con el artículo 164 del Código Orgánico de Tribunales", Revista de Estudios de la Justicia n ${ }^{\circ} 14$ (2011), pp. 199-216, pp. 205 y ss. En contra, implícitamente, CERDA SAN MARTÍN, Rodrigo, "La unificación de penas contemplada en el artículo 164 del Código Orgánico de Tribunales", Revista de Justicia Penal n 2 (2008), pp. 187-208, pp. 192 y ss.

${ }^{13}$ Vid. RODRÍGUEZ COLLAO, Luis; OLIVER CALDERÓN, Guillermo, "Aplicabilidad de la figura del delito continuado en los delitos sexuales. Comentario a un fallo", Revista de Derecho, Universidad Católica del Norte ${ }^{\circ} 1$, año 16 (2009), pp. 251-264, p. 254.

${ }^{14}$ Cfr. LÓPEZ L., Osvaldo, Derecho Procesal Penal Chileno, $2^{a}$ ed., Santiago: Ediar Editores, 1983, p. 40.
} 
Público. En el actual sistema de enjuiciamiento criminal, el órgano persecutor, en su calidad de director de la investigación penal, decide, por razones de conveniencia, ${ }^{15}$ agrupar o separar investigaciones (art. $185 \mathrm{CPP}$ ). Este cambio es significativo, pues si antes la unificación de penas corregía una distorsión punitiva que se introducía en la persecución penal de varios hechos por razones puramente procedimentales, hoy, por ser la agrupación o separación de investigaciones una atribución del Ministerio Público, la mencionada distorsión puede fundarse en razones de política criminal, de estrategia en la persecución de la criminalidad, o de simples necesidades administrativas del servicio. En todo caso, debe tenerse presente que también el juez de garantía podría dar ocasión para que se produjera la señalada distorsión, al separar acusaciones para hechos distintos imputados a una misma persona, lo que no sólo podría fundarse en la necesidad de impedir un detrimento en su derecho de defensa, sino también en la de evitar dificultades en la organización o desarrollo del juicio, o sea, por razones exclusivamente procedimentales (art. $274 \mathrm{CPP}$ ).

Como puede apreciarse, las características del nuevo sistema procesal penal hacían necesario introducir cambios en la llamada unificación de penas, los que se concretaron en el actual artículo 164 del Código Orgánico de Tribunales. Si esto no se hubiera hecho, habría sido imposible en muchos casos mitigar los perniciosos efectos de la aplicación de la regla de acumulación aritmética de las penas, utilizando las reglas concursales que constituyen excepciones a aquélla. ${ }^{16}$ La decisión adoptada por el legislador, entonces, es digna del mayor encomio.

\section{Significado actual de la unificación.}

Uno de los problemas que se observan en la práctica es el de la errada aplicación que suele hacerse del citado artículo 164, debido a una equivocada comprensión del sentido actual de la unificación de penas. Es común que tribunales de la reforma procesal penal (Tribunales de Juicio Oral en lo Penal y Juzgados de Garantía) apliquen el procedimiento que se encontraba previsto en el antiguo artículo 160 del Código Orgánico de Tribunales para los jueces del crimen, esto es, dictar una sentencia posterior a todas las condenas pronunciadas, incluso por otros tribunales, que abarque la totalidad de los hechos que ya han sido juzgados, e imponer al imputado una pena única, unificada. ${ }^{17}$ De acuerdo con la

\footnotetext{
15 HORVITZ LENNON, María Inés; LÓPEZ MASLE, Julián, Derecho Procesal Penal Chileno, t. I, Santiago: Editorial Jurídica de Chile, 2002, pp. 206 y ss., 455.

${ }^{16}$ Similar, MORALES ESPINOZA, "La regulación de la pena", cit. nota no 12, p. 203.

17 Véanse, por ejemplo, entre muchas otras, la sentencia del Tribunal de Juicio Oral en lo Penal de Concepción, de 7 de mayo de 2007, dictada en causa RUC No 06000046146-4; la sentencia del Segundo Tribunal de Juicio Oral en lo Penal de Santiago, de 22 de junio de 2007, dictada en causa RUC N 0600023991-6, y la sentencia del Tribunal de Juicio Oral en lo Penal de Copiapó, de 30 de mayo de 2006, dictada en causa RUC $\mathrm{N}^{\mathrm{0}}$ 04000744025-5, todas citadas en DEFENSORÍA REGIONAL METROPOLITANA NORTE, Documento de trabajo No 20: “Acumulación o unificación de penas", Santiago: 2007, diciembre, pp. 10-24. Véase también la sentencia de la Corte de Apelaciones de Santiago, de 21 de septiembre de 2009, dictada en causa rol No 1795-2009. Téngase además presente que, en opinión de VAN WEEZEL, "Unificación de las penas", cit. nota $\mathrm{n}^{\circ}$ 2, p. 56, el mencionado artículo 160, si bien
} 
OLIVER, Guillermo. "Aproximación a la unificación de penas".

regulación actual de la figura y con la estructura del nuevo proceso penal, no es posible que un tribunal modifique un fallo que ha pronunciado con anterioridad, ${ }^{18}$ ni menos uno que ha sido dictado por otro tribunal. ${ }^{19}$ Matus Acuña ha hecho notar este gran cambio en la institución en análisis, al advertir que el texto del antiguo artículo 160, por utilizar la voz unificación, y considerando que las diversas sentencias eran dictadas por un mismo tribunal, parecía admitir la posibilidad de modificar los fallos anteriores y sustituirlos por una sentencia final que unificara todas las penas. Hoy, en cambio, es claro que al usar el artículo 164 la expresión fallo posterior, lo que se ordena es, simplemente, que el tribunal adapte su sentencia en consideración de las condenas anteriores que cumplan los requisitos para ser tenidas en cuenta según esta figura. ${ }^{20}$ Por lo tanto, no puede unificar las penas anteriormente impuestas por otros tribunales con la que imponga él. Sólo puede, para ajustar su sentencia y no superar el límite que el precepto establece, (a) disminuir la pena que va a imponer o que ya impuso; (b) condenar sin imponer pena alguna o modificar la sentencia condenatoria que ha dictado para no imponer pena (cuando el hacerlo implicaría exceder el máximo de pena que pudiera imponerse) ${ }^{21}$ (c) condenar, pero otorgar algún beneficio compatible con la pena que habría podido imponer en un eventual juzgamiento conjunto o modificar la sentencia condenatoria que ha dictado para otorgar un beneficio compatible con dicho juzgamiento, ${ }^{22}$ y (d) considerar atenuantes o descartar agravantes en la condena que dicte o modificar la sentencia condenatoria que ha dictado para considerarlas o descartarlas, respectivamente. En otras palabras, el tribunal nada tiene que unificar; sólo debe preocuparse de regular la pena que él impone, de modo que la suma de ella con las anteriores no exceda el mencionado límite. ${ }^{23}$

contemplaba la obligación de "sumar penas" en la última sentencia unificadora, no permitía crear una pena "global" o "conjunta".

${ }^{18}$ Excepto la hipótesis del tercer inciso del artículo 18 del Código Penal.

${ }^{19}$ Salvo cuando aquél conoce y acoge un recurso interpuesto contra una sentencia pronunciada por éste.

${ }^{20}$ MATUS ACUÑA, "Proposiciones", cit. nota $\mathrm{n}^{\circ}$ 4, p. 542; EL MISMO, "Comentario a la SCA de Temuco de 1 de diciembre de 2008. Rol 1100/2008", Doctrina y jurisprudencia penal. Revista de Derecho de la Universidad de Los Andes, El engaño y el error en la estafa, $\mathrm{n}^{\circ} 1$ (2010), pp. 114-124, p. 118.

${ }^{21}$ MATUS ACUÑA, "Proposiciones", cit. nota n ${ }^{\circ} 4$, p. 544, nota 54.

${ }^{22}$ En consecuencia, podría el tribunal conceder en su sentencia condenatoria el beneficio de la remisión condicional de la pena, a pesar de que el imputado haya sido antes condenado por crimen o simple delito, siempre que los delitos anteriores hayan podido juzgarse conjuntamente con el delito posterior y la pena que se habría podido aplicar en tal evento hubiera sido compatible con dicho beneficio. En este sentido, MORALES ESPINOZA, "La regulación de la pena", cit. nota ${ }^{\circ}$ 12, p. 211. En contra, MATUS ACUÑA, "Proposiciones", cit. nota n ${ }^{\circ}$, pp. 544 y ss.

Por otra parte, cuando en su sentencia condenatoria el tribunal impone una pena por cuya cuantía resulta procedente el beneficio de la remisión condicional, puede concederlo, a pesar de que el hecho objeto del proceso haya podido ser juzgado conjuntamente con los hechos anteriores, y de que en dicho evento la pena que se habría podido aplicar hubiera sido incompatible con tal beneficio. En contra, véase SÁNCHEZ PIAZZA, José Manuel, La regla de determinación de la pena contemplada en el artículo 164 del Código Orgánico de Tribunales, Valparaíso: Tesis Pontificia Universidad Católica de Valparaíso, 2012, pp. 56 y ss.

${ }^{23}$ Véase DEFENSORÍA REGIONAL METROPOLITANA NORTE. UNIDAD DE ESTUDIOS, Documento de trabajo $\mathrm{N}^{\circ} 20$, cit. nota $\mathrm{n}^{\circ} 17$, p. 8 , donde se reconoce que en la jurisprudencia se advierten ambas formas de proceder, la "unificadora" y la simplemente "reguladora" de la pena del fallo posterior, y se admite que es la segunda la jurídicamente correcta. 
Polít. crim. Vol. 7, No 14 (Diciembre 2012), Art. 1, pp. 248 - 275.

[http://www.politicacriminal.cl/Vol_07/n_14/Vol7N14A1.pdf]

Para ello, cada tribunal que dicte condena contra alguien que ya ha sido sancionado por un hecho distinto, ${ }^{24}$ siempre que se cumplan todos los requisitos de la figura, debe dar los siguientes pasos: a) calcular la pena concreta que corresponda imponer al hecho que se juzga en forma posterior; b) calcular la pena que habría correspondido imponer si tal hecho hubiera sido juzgado conjuntamente con los otros, para determinar si es posible aplicar un régimen concursal más favorable al imputado, y c) en caso efectivo, regular la pena a imponer por el hecho que se juzga en forma posterior, de modo que "el conjunto de penas no pueda exceder de aquella que hubiere correspondido de haberse juzgado conjuntamente los delitos". ${ }^{25}$ Como puede verse, las actuales posibilidades de actuación del tribunal son, entonces, bastante más restringidas que las que el antiguo artículo 160 le concedía.

Un sector de la doctrina ${ }^{26}$ y gran parte de la jurisprudencia siguen utilizando la denominación unificación de penas, que se encontraba en la literalidad del antiguo artículo 160 del Código Orgánico de Tribunales, para referirse al mecanismo de regulación de penas del actual artículo 164 del mismo Código, a pesar de que dicha nomenclatura fue adoptada sobre la base del texto del primero. Como hemos visto, razones de texto y sistemáticas abonan la afirmación de que se trata de figuras diferentes, lo que permite concluir que pese a que tienen un mismo fundamento, sus efectos en materia de determinación de la pena son distintos. La denominación unificación de penas debería quedar reservada, entonces, para el antiguo artículo 160 del Código Orgánico de Tribunales (y para el aún vigente artículo 12 del Código de Justicia Militar); para hacer referencia al mecanismo contemplado en el actual artículo 164 del Código Orgánico de Tribunales debería utilizarse una terminología distinta. ${ }^{27}$ En todo caso, tal vez más importante que la denominación que se dé a esta última figura, es que se la aplique respetando su actual conformación.

\section{Requisitos de la figura.}

\subsection{Pluralidad de sentencias condenatorias.}

Esta exigencia aparece explícitamente formulada en la primera parte del artículo 164 del Código Orgánico de Tribunales ("Cuando se dictaren distintas sentencias condenatorias...") y ha dado lugar a algunas dudas en la doctrina. Por ejemplo, se ha examinado la posibilidad de aplicar la figura a sentencias condenatorias dictadas por tribunales del antiguo y del actual sistema de enjuiciamiento criminal, como a un fallo de

\footnotetext{
${ }^{24}$ No sólo debe hacer esto el tribunal que dicte "la última sentencia", expresión que se contenía en el proyecto de la Ley N 19.665 y que se sustituyó por la de "fallo posterior", para comprender las hipótesis de fallos condenatorios sucesivos en contra de un mismo imputado. Véase el informe de la Comisión de Constitución, Legislación, Justicia y Reglamento del Senado, de 20 de diciembre de 1999, Boletín 2263-07, en BIBLIOTECA DEL CONGRESO NACIONAL DE CHILE, Historia de la Ley $N^{o}$ 19.665, p. 405, en http://www.bcn.cl/histley/lfs/hdl-19665/HL19665.pdf [visitado el 06.07.2012].

${ }^{25}$ MATUS ACUÑA, "Proposiciones", cit. nota $n^{\circ} 4$, p. 542; MORALES ESPINOZA, "La regulación de la pena", cit. nota $n^{\circ} 12$, p. 203.

${ }^{26}$ Véase CERDA SAN MARTÍN, "La unificación de penas", cit. nota n 12, pp. 187-208.

${ }^{27}$ Por esta razón, en varias partes de este trabajo hemos escrito la voz unificación entre comillas.
} 
OLIVER, Guillermo. “Aproximación a la unificación de penas”.

un Juzgado del Crimen y a otro de un Juzgado de Garantía o de un Tribunal de Juicio Oral en lo Penal ${ }^{28}$.

La verdad es que este problema ha sido normativamente resuelto en el sentido de permitir la aplicación de la figura en el caso señalado, ya que según el artículo transitorio del Código Procesal Penal,

"si una persona hubiere cometido distintos hechos, debido a los cuales fuere juzgada por un juzgado de letras del crimen o con competencia en lo criminal, con sujeción al Código de Procedimiento Penal, y también lo fuere por un juzgado de garantía o un tribunal oral en lo penal conforme a este Código, en el pronunciamiento de las sentencias condenatorias que se dictaren con posterioridad a la primera se estará a lo previsto en el artículo 164 del Código Orgánico de Tribunales".

A pesar de que el citado artículo transitorio sólo alude a los Juzgados de Garantía y a los Tribunales de Juicio Oral en lo Penal, por lo que no quedaría dentro de su radio de acción el caso en que fuera otro el tribunal que dictara condena en el actual sistema procesal penal (por ejemplo, una Corte), no parece que sea problemático aplicarlo analógicamente en esta hipótesis, toda vez que ello importaría un evidente beneficio para el imputado. ${ }^{29}$

Tampoco existe inconveniente en aplicar la figura cuando las distintas sentencias condenatorias han sido dictadas en el actual sistema procesal penal por tribunales penales de diferente índole, como Juzgados de Garantía (en procedimientos monitorio, simplificado, abreviado o por delito de acción privada), Tribunales de Juicio Oral en lo Penal (en juicio oral), Cortes de Apelaciones (en la segunda instancia del procedimiento abreviado o al dictar sentencia de reemplazo en un recurso de nulidad por errónea aplicación del derecho) o incluso la Corte Suprema (en los casos en que, excepcionalmente, ésta puede conocer un recurso de nulidad por errónea aplicación del derecho y dictar en él sentencia de reemplazo). Ello es así, porque el citado artículo 164 alude genéricamente a los tribunales, sin efectuar distingo alguno. ${ }^{30}$

Una situación problemática podría plantearse cuando las diversas sentencias condenatorias han sido pronunciadas en procedimientos simplificados con admisión de responsabilidad o en procedimientos abreviados, ${ }^{31}$ en los cuales, como es sabido, el juez de garantía no puede imponer una pena superior a la solicitada por el fiscal en su requerimiento o en su acusación, respectivamente (arts. 395 inc. $2^{\circ}$ y 412 inc. $1^{\circ} \mathrm{CPP}$ ). En tales casos, surge la duda de si el tribunal que dicta el fallo posterior debe respetar los límites de las penas solicitadas por el fiscal que han motivado la aceptación del imputado en los procesos anteriores o si puede prescindir de ellos, cuando realiza el cálculo de la pena que podría haberse impuesto si hubiera existido un juzgamiento conjunto. Según mi opinión, dichos límites sí deben ser considerados por el tribunal que dicta la sentencia posterior al efectuar

\footnotetext{
${ }^{28}$ CERDA SAN MARTÍN, "La unificación de penas", cit. nota no 12, p. 190; MORALES ESPINOZA, "La regulación de la pena", cit. nota $\mathrm{n}^{\mathrm{o}}$ 12, p. 204.

${ }_{29}^{29}$ Así, SÁNCHEZ PIAZZA, La regla de determinación de la pena, cit. nota no 22, p. 34, nota 101.

${ }^{30}$ En el mismo sentido, CERDA SAN MARTÍN, "La unificación de penas", cit. nota $\mathrm{n}^{\circ} 12$, p. 191; MORALES ESPINOZA, "La regulación de la pena", cit. nota nº 12, p. 204.

${ }^{31}$ Lo reconoce CERDA SAN MARTÍN, "La unificación de penas", cit. nota no 12, p. 191.
} 
Polít. crim. Vol. 7, No 14 (Diciembre 2012), Art. 1, pp. 248 - 275.

[http://www.politicacriminal.cl/Vol_07/n_14/Vol7N14A1.pdf]

el mencionado cálculo, ya que lo contrario implicaría que el condenado pudiera perder la atenuación de pena que tuvo en cuenta al renunciar a su derecho a un juicio oral, admitiendo responsabilidad en el procedimiento simplificado o aceptando los hechos de la acusación en el procedimiento abreviado. ${ }^{32}$

\subsection{Posibilidad de juzgamiento conjunto.}

Este requisito está implícitamente establecido en el artículo 164 del Código Orgánico de Tribunales, en las frases "...de haberse acumulado los procesos..." y "...de haberse juzgado conjuntamente los delitos...".

Llama la atención el hecho de que en la primera de las oraciones recién transcritas, el legislador utilice la expresión acumulación, ya que, como hemos visto, el desacumular procesos era algo que en el anterior sistema de enjuiciamiento criminal podía excepcionalmente ordenar el juez del crimen, en los casos que contemplaba el inciso segundo del antiguo artículo 160 del Código Orgánico de Tribunales. La acumulación obligatoria de procesos fue sustituida en el actual sistema procesal penal por una agrupación de investigaciones que puede disponer el Ministerio Público y por una unión de acusaciones que puede ordenar el juez de garantía. Indudablemente, se trata de un lapsus calami, probablemente debido a reminiscencias del antiguo sistema de procedimiento penal. ${ }^{33}$ Lo decisivo es lo que fluye de la lectura de la segunda de las frases transcritas, esto es, que el hecho que se juzga en forma posterior haya sido posible de ser juzgado conjuntamente con los hechos que lo fueron en las sentencias condenatorias anteriores. Es en este sentido en el que debe entenderse la alusión a la acumulación de procesos, de la primera frase.

En todo caso, hay discusión acerca de cuándo ha existido dicha posibilidad de juzgamiento conjunto. Sistematizando las opiniones doctrinales y jurisprudenciales que se han emitido sobre este punto, ellas podrían ser agrupadas en los siguientes tres planteamientos, uno de los cuales he denominado restrictivo; otro, intermedio y otro, extensivo:

i) Planteamiento restrictivo: una primera forma de entender este requisito consiste en exigir que los diversos procesos tramitados en forma separada, se hayan sustanciado simultáneamente en el tiempo, al menos en parte, ya que sólo de este modo podría habérselos "acumulado".

ii) Planteamiento intermedio: una segunda manera de entenderlo consiste en exigir que entre los hechos juzgados en forma separada no medie una sentencia condenatoria firme, ya que sólo así podría aplicarse alguna regla sobre concurso de delitos que resulte más favorable para el imputado.

iii) Planteamiento extensivo: una tercera manera de comprender el requisito en análisis consiste en exigir cierta cercanía temporal entre cada uno de los hechos juzgados en forma

\footnotetext{
${ }^{32}$ Así, MORALES ESPINOZA, "La regulación de la pena”, cit. nota no 12, pp. 204 y ss.

${ }^{33}$ En el mismo lapsus incurrió el Ejecutivo en el artículo 362 del proyecto de ley que dio lugar al Código Procesal Penal. En dicho texto, que fue el antecedente del actual artículo 274 del mencionado Código, se hablaba de acumulación de juicios, expresión que fue eliminada por el Senado, por ser una nomenclatura propia del antiguo procedimiento penal. Cfr. PFEFFER URQUIAGA, Emilio, Código Procesal Penal anotado y concordado, $2^{a}$ ed., Santiago: Editorial Jurídica de Chile, 2006, p. 421.
} 
OLIVER, Guillermo. “Aproximación a la unificación de penas”.

separada, aun cuando respecto de alguno de ellos se haya dictado sentencia condenatoria ejecutoriada.

El planteamiento restrictivo ha sido formulado en algunas sentencias que, para analizar la posibilidad de abonar a la condena dictada en una causa el tiempo sufrido por el imputado en prisión preventiva decretada en una causa diversa - lo que en doctrina se conoce como "abono heterogéneo"-, ${ }^{34}$ han acudido al artículo 164 del Código Orgánico de Tribunales, interpretando el requisito en estudio en la forma señalada. ${ }^{35}$

Según mi opinión, este planteamiento no resulta aceptable, ya que, atendidas las características del nuevo sistema procesal penal, conduce a reconocer a la "unificación" de penas un campo de aplicación tan reducido, que no parece compatible con el fundamento de la figura. En el actual sistema, la única forma de que dos procesos que se tramitan separadamente se "acumulen", es mediante la agrupación de investigaciones que disponga el fiscal (art. 185 CPP) o la unión de acusaciones que ordene el juez de garantía (art. 274 CPP). Lo primero puede hacerse sólo mientras las dos investigaciones se mantengan abiertas; lo segundo, únicamente en la audiencia de preparación del juicio oral. En consecuencia, si en alguna de las dos causas que se tramitan en forma separada ya se hubiera llegado a la etapa de juicio oral, la tramitación conjunta de ambas resultaría imposible. Imaginemos, por ejemplo, que en el proceso que se sigue contra alguien se está a días de celebrar el juicio oral cuando el mismo imputado comete un nuevo delito, de la misma especie que el anterior, iniciándose una investigación por el nuevo hecho. En un caso como éste, conforme al planteamiento restrictivo, no podría aplicarse el mencionado artículo 164, porque las dos causas no podrían unirse, y el imputado se vería privado, entonces, de la posibilidad de que al dictarse una nueva sentencia condenatoria, ahora por el segundo hecho, se regule la pena sin que la suma de ella con la anterior exceda el límite de la regla de reiteración de delitos de la misma especie (art. $351 \mathrm{CPP}$ ), en el caso de resultarle más conveniente. En cambio, en el antiguo procedimiento penal, de corte inquisitivo, el inculpado sí podía verse beneficiado en una situación como ésta (nuevo delito cometido por el reo durante el plenario), ya que era aplicable lo que disponía el artículo 160 del Código Orgánico de Tribunales ("El culpable de diversos delitos será juzgado por todos ellos en un solo proceso, para lo cual se acumularán las causas iniciadas o por iniciarse en su contra..."). Esto demuestra la incorrección de esta tesis, porque conduce al absurdo de concluir que el nuevo sistema procesal penal, mucho más compatible con los postulados de un Estado social y democrático de derecho que el anterior, permitiría la imposición de penas desproporcionadas que ni aun en el vetusto procedimiento inquisitivo se podían aplicar.

\footnotetext{
${ }^{34}$ Sobre el tema, véase GUZMÁN DALBORA, José Luis, "El abono de las medidas cautelares a la pena", Revista Procesal Penal, no 72 (2008), pp. 9-20; HERNÁNDEZ BASUALTO, Héctor, "Abono de prisión preventiva en causa diversa", Informes en Derecho. Doctrina Procesal Penal 2009, no 7 (2010, octubre), pp. 109-120.

${ }^{35}$ Entre otras sentencias pronunciadas en este sentido, pueden verse las de la Corte Suprema, de 27 de agosto de 2009, dictada en causa rol No 5798-2009, y de 5 de abril de 2010, dictada en causa rol № 2221-2010. Véase también la sentencia del Tribunal de Juicio Oral en lo Penal de Los Andes, de 2 de septiembre de 2011, dictada en causa RUC 0900690395-6, RIT 20-2010.
} 
Polít. crim. Vol. 7, No 14 (Diciembre 2012), Art. 1, pp. 248 - 275.

[http://www.politicacriminal.cl/Vol_07/n_14/Vol7N14A1.pdf]

El planteamiento extensivo, que ha sido expuesto en varias sentencias ${ }^{36}$ y cuenta con algún respaldo doctrinal, ${ }^{37}$ tampoco me parece admisible, por varias razones. En primer lugar, por no ser de utilidad en la aplicación de la figura en análisis, al resultar extremadamente vaga la referencia a la proximidad temporal entre los hechos. Los partidarios de esta tesis suelen emplear la expresión "conexión temporal razonable" para aludir a esta idea, pero no aportan criterios para precisar hasta cuándo la cercanía temporal sería razonable y desde cuándo dejaría de serlo.

Por otro lado, este planteamiento, al no conceder ninguna importancia al hecho de que alguno de los delitos haya sido sancionado por sentencia firme, conduce a privar de aplicación a la agravante de reincidencia. ${ }^{38}$ En efecto, si quien ya ha sido condenado por sentencia ejecutoriada por un delito vuelve a delinquir, bastaría simplemente que existiera proximidad temporal entre ambos hechos para poder aplicar la figura en estudio, lo que implicaría negar lugar a dicha agravante, ya que conforme al artículo 164 del Código Orgánico de Tribunales, el tribunal que juzgue el segundo hecho no podría "considerar circunstancias modificatorias que de haberse acumulado los procesos no se hubieren podido tomar en cuenta". La "unificación" de penas no se ha creado para esto, sino para que el juzgamiento separado de dos o más hechos, no impida la aplicación de las reglas concursales que constituyen una excepción a la regla de la acumulación aritmética, cuando esto resulte más favorable para el imputado. Parecería absurdo que mientras, por una parte, el legislador asigna efecto agravatorio a la reincidencia, por la otra, lo excluyera por el simple hecho de que transcurra poco tiempo entre el primer delito y aquel en que se reincide. Una interpretación sistemática conduce justo a la conclusión contraria: es el transcurso de un largo lapso entre ambos delitos lo que excluye dicho efecto agravatorio, en la llamada "prescripción de la reincidencia" (art. $104 \mathrm{CP}$ ).

Avala lo anterior la justificación que suele atribuirse a la agravación de la pena del reincidente. A quien es condenado se le formula en la sentencia un juicio de reproche por el delito cometido y se le advierte que si vuelve a delinquir la reacción penal será más intensa. Es incompatible con esta idea la búsqueda de un tratamiento punitivo más benigno a través de la aplicación del citado artículo 164.

Además, este planteamiento conlleva el peligro de otorgar un "crédito" que podría incentivar al condenado a seguir delinquiendo sin temer consecuencias penales. Si con la condena anterior por varios delitos ya se ha alcanzado el límite máximo de la regla concursal de que se trate (verbigracia, la de la reiteración de delitos de la misma especie), los nuevos delitos que el imputado cometiera después de la condena (próximos en el tiempo a los anteriores) deberían quedar en la impunidad, lo cual no parece razonable. ${ }^{39}$

\footnotetext{
${ }^{36}$ Entre otros, véanse los fallos del Segundo Tribunal de Juicio Oral en lo Penal de Santiago, de 18 de febrero de 2011, dictado en causa RUC 1000325554-4, RIT 218-2010, y de 31 de marzo de 2011, dictado en causa RUC 0700811709-2, RIT 125-2009.

${ }^{37}$ CERDA SAN MARTÍN, “La unificación de penas", cit. nota n 12, p. 193.

${ }^{38}$ La opinión negativa que me merece la consagración de dicha agravante en el Código Penal chileno no interesa para estos efectos.

${ }^{39}$ Véase MENDAÑA, Ricardo Jorge, “Unificación de penas”, Revista Jurídica Argentina La Ley, C (1978), pp. 720-728, p. 723, quien esgrime una argumentación similar para sostener, contra lo que afirma un sector al parecer mayoritario de la doctrina argentina, que la regla de unificación de penas que se contiene en el
} 
OLIVER, Guillermo. “Aproximación a la unificación de penas”.

En síntesis, según mi opinión, si se quisiera que la figura en análisis se aplicase incluso a hechos ejecutados después de una condena firme, la ley tendría que decirlo expresamente, siguiendo el ejemplo de otras legislaciones que así lo han hecho. ${ }^{40}$

Finalmente, el planteamiento intermedio, que también se encuentra en algunas sentencias ${ }^{41}$ $\mathrm{y}$ ha sido formulado por un sector de la doctrina, ${ }^{42}$ es a mi juicio, el que se ajusta mejor al fundamento de la figura en estudio. En efecto, si su finalidad es hacer operativas en el juzgamiento de varios hechos reglas concursales más favorables, que no pudieron aplicarse porque tales hechos fueron objeto de juzgamiento separado, es imprescindible que entre ellos (y respecto de ellos) no medie una sentencia condenatoria firme. La unanimidad de la doctrina exige como uno de los requisitos del concurso material de delitos, que respecto de ninguno de los hechos que lo integran se haya pronunciado una sentencia ejecutoriada. ${ }^{43}$ De ahí que la exigencia de posibilidad de juzgamiento conjunto sólo pueda significar que entre los diversos delitos no exista una condena firme a su respecto. Así y por ejemplo, dos delitos de la misma especie no se pueden sancionar conforme a la regla del artículo 351 del Código Procesal Penal, si el segundo se comete después de haberse dictado condena firme por el primero; en este caso no será aplicable el artículo 164 del Código Orgánico de Tribunales, por no cumplirse el requisito en análisis, y podría eventualmente apreciarse la agravante de reincidencia, siempre que concurran todos sus presupuestos. En cambio, si el segundo delito se comete antes de haberse dictado condena firme por el primero, se cumplirá el requisito en estudio y será aplicable el citado artículo 164, aun cuando el hecho se descubra después de dicha sentencia, y a pesar de que en este último caso ya no sea posible una tramitación conjunta de los procesos.

artículo 58 del Código Penal de dicho país no alcanza a los reincidentes. Sosteniendo una opinión contraria, puede verse ZAFFARONI, Eugenio Raúl; ALAGIA, Alejandro; SLOKAR, Alejandro, Derecho Penal: Parte General, $2^{a}$ ed., Buenos Aires: Ediar, 2003, pp. 1016 y ss. La parte pertinente del texto de la citada disposición es la siguiente: "Las reglas precedentes se aplicarán también en el caso en que después de una condena pronunciada por sentencia firme se deba juzgar a la misma persona que esté cumpliendo pena por otro hecho distinto [...]. Corresponderá al juez que haya aplicado la pena mayor dictar, a pedido de parte, su única sentencia, sin alterar las declaraciones de hechos contenidas en las otras".

${ }^{40}$ Es el caso, por ejemplo, del Código Penal venezolano, en cuyo artículo 97 se dispone lo siguiente: "Las reglas contenidas en los anteriores artículos se aplicarán al caso en que, después de una sentencia condenatoria, haya de ser juzgada la misma persona por otro hecho punible cometido antes de la condena $o$ después de ésta, pero mientras esté cumpliéndola. Mas, si la pena se hubiere cumplido o se hubiere extinguido la condena antes que la nueva sea ejecutable, se castigará el nuevo hecho punible con la pena que le corresponda". Otro tanto sucede en el Código Penal italiano, cuyo artículo 80 reza así: "Las disposiciones de los artículos precedentes se aplican también en el caso en que, después de una sentencia o de un decreto de condena, se deba juzgar a la misma persona por otro delito cometido con anterioridad o posterioridad a la condena misma, o bien cuando contra la misma persona se deban ejecutar más sentencias o más decretos de condena" (traducción libre).

${ }^{41}$ Entre otras sentencias, véanse la de la Corte de Apelaciones de San Miguel, de 5 de diciembre de 2008, dictada en causa rol No 1451-2008, y la del Tribunal de Juicio Oral en lo Penal de Copiapó, de 6 de diciembre de 2006, dictada en causa RUC 0410002543-K, RIT 127-2004.

${ }^{42}$ Cfr. MATUS ACUÑA, "Comentario", cit. nota no 20, p. 118; EL MISMO, "Proposiciones", cit. nota no 4, p. 541; MORALES ESPINOZA, "La regulación de la pena", cit. nota no 12, pp. 206 y ss.

${ }^{43}$ Por todos, véase CURY URZÚA, Enrique, Derecho Penal: Parte General, $9^{a}$ ed., Santiago: Ediciones Universidad Católica de Chile, 2009, pp. 659 y ss. 
Polít. crim. Vol. 7, No 14 (Diciembre 2012), Art. 1, pp. 248 - 275.

[http://www.politicacriminal.cl/Vol_07/n_14/Vol7N14A1.pdf]

De acuerdo con esta forma de comprender el requisito objeto de análisis, ninguna importancia tiene el hecho de que alguna de las penas impuestas por las sentencias condenatorias anteriores o todas ellas se encuentren cumplidas. Un sector de la doctrina y de la jurisprudencia lo niega, argumentando que cuando las penas anteriores se han cumplido, la responsabilidad penal se ha extinguido, por lo que no habría penas que unificar. $^{44}$ La verdad es que ni explícita ni implícitamente el mencionado artículo 164 exige que las penas anteriores no estén cumplidas y tampoco hay una razón material para que el intérprete lo requiera, restringiendo injustificadamente el ámbito de aplicación de la figura. Recuérdese que el tribunal nada tiene que unificar. Lo que este precepto busca es facilitar la aplicación de reglas concursales más favorables, evitando la imposición de penas desproporcionadas. Que ellas ya se hayan cumplido o aún no lo hayan sido es completamente indiferente para dicho propósito. Aun cuando hayan sido cumplidas, deben ser consideradas en el cálculo penológico que haga el tribunal del fallo ulterior, si los hechos por los que se impusieron pudieron juzgarse conjuntamente con el hecho que se juzga con posterioridad, ${ }^{45}$ porque la consideración de dichas penas anteriores en el mencionado cálculo penológico podría dar lugar al exceso que se pretende evitar. Sólo podría exigirse como requisito que las penas anteriores no estén cumplidas si la ley lo estableciera expresamente, tal como lo hacen algunas legislaciones extranjeras. ${ }^{46}$

\subsection{Otros requisitos.}

Aun cuando el artículo 164 del Código Orgánico de Tribunales no lo menciona explícitamente, es obvio que para aplicar la regla de determinación de pena que dicho precepto establece, es necesario que las diversas sentencias condenatorias que se dicten contra un mismo imputado recaigan sobre hechos distintos. ${ }^{47}$ Por algo el artículo transitorio del Código Procesal Penal alude expresamente a esta exigencia (“...si una persona hubiere cometido distintos hechos..."). Si la segunda condena recae sobre el mismo hecho por el cual se dictó la primera, lo procedente no es hacer aplicación del señalado mecanismo de regulación de la pena, sino impugnar aquélla a través de un recurso de nulidad (art. 374 letra g CPP).

También es evidente que la limitación penológica que establece el primer inciso del citado artículo 164 y la modificación de sentencia a que obliga su inciso segundo, sólo cobran vigor si la penalidad que habría correspondido imponer a los diversos hechos, de haber sido juzgados conjuntamente, hubiera sido inferior a la suma de las penas impuestas por

\footnotetext{
${ }^{44}$ En este sentido, CERDA SAN MARTÍN, "La unificación de penas", cit. nota $\mathrm{n}^{\circ}$ 12, p. 193. Véase también DEFENSORÍA REGIONAL METROPOLITANA NORTE. UNIDAD DE ESTUDIOS, Documento de trabajo $N^{o} 20$, cit. nota $\mathrm{n}^{\circ} 17$, p. 5. Similar, pero aludiendo al artículo 38 de la ley de drogas anterior a la actualmente vigente, es decir, a la Ley No 19.366, de 1995, DÍAZ CRUZAT, "Esquema", cit. nota nº 3, pp. 147 y ss.; EL MISMO, "Problemas anexos", cit. nota nº 3, p. 7.

${ }^{45}$ Así, MORALES ESPINOZA, "La regulación de la pena", cit. nota no 12, p. 207.

${ }^{46}$ Es el caso, por ejemplo, de los Códigos Penales argentino (art. 58) y paraguayo (art. 71).

${ }^{47}$ En este sentido, CERDA SAN MARTÍN, "La unificación de penas", cit. nota $n^{\circ} 12$, p. 192; MORALES ESPINOZA, "La regulación de la pena", cit. nota nº 12, p. 205.
} 
OLIVER, Guillermo. “Aproximación a la unificación de penas”.

separado. ${ }^{48}$ En otras palabras, para aplicar esta disposición es necesario que haya existido la posibilidad de un tratamiento punitivo más benigno.

\section{Consideración de circunstancias modificatorias.}

Conforme a lo que indica la primera parte del artículo 164 del Código Orgánico de Tribunales,

"cuando se dictaren distintas sentencias condenatorias en contra de un mismo imputado, los tribunales que dictaren los fallos posteriores al primero no podrán considerar circunstancias modificatorias que de haberse acumulado los procesos no se hubieren podido tomar en cuenta".

Con independencia de la ya señalada incorrección de la expresión "acumulación de procesos", lo que en este momento interesa destacar del texto transcrito es que, aparentemente, impide al tribunal del fallo posterior considerar cualquier circunstancia modificatoria que no se habría podido tomar en cuenta si los diversos hechos se hubieran juzgado en forma conjunta. Sin embargo, un análisis más detallado del punto demuestra que tal afirmación debe ser matizada.

Tratándose de agravantes, es evidente que dicha aseveración resulta válida. Dado que con esta disposición se pretende que el imputado no se vea perjudicado por la decisión adoptada por otras personas, de que se juzguen en forma separada hechos que podrían haberse juzgado conjuntamente, si en un eventual juzgamiento conjunto no podría haberse considerado una determinada agravante, tampoco podría tomársela en cuenta por el tribunal que dicta el fallo condenatorio posterior.

No obstante, cuando se trata de una atenuante, la situación es distinta. Si en el juzgamiento ulterior el tribunal estima concurrente la circunstancia, a mi juicio, debería aplicarla, a pesar de que si el hecho se hubiera juzgado conjuntamente con el delito anterior no se habría podido tomar en cuenta. Es cierto que la literalidad del precepto alude genéricamente a las circunstancias modificatorias, sin distinguir entre atenuantes y agravantes, pero una interpretación teleológica conduce a la señalada conclusión. Carece de sentido perjudicar al imputado en este caso, toda vez que la disposición ha sido creada con el fin de beneficiarle. Refuerza esta idea la constatación de que inmediatamente después de la referencia genérica a las circunstancias modificatorias, la norma legal impide al tribunal del fallo posterior imponer una pena que, sumada a la anteriormente aplicada, excedería de la que se podría haber impuesto en un eventual juzgamiento conjunto. Esto último parece sugerir cuál es la razón de la previsión legal anterior. La improcedencia de considerar en la sentencia posterior circunstancias modificatorias que no podrían haberse tomado en cuenta si los hechos se hubieran juzgado conjuntamente, sólo se explica en la medida en que de ese modo se evita un perjuicio para el imputado. Por lo tanto, cuando dicha imposibilidad priva a éste de un beneficio punitivo -como lo es la consideración de

\footnotetext{
${ }^{48}$ Cfr. CERDA SAN MARTÍN, "La unificación de penas", cit. nota no 12, p. 193; MORALES ESPINOZA, "La regulación de la pena", cit. nota n 12, p. 208.
} 
Polít. crim. Vol. 7, No 14 (Diciembre 2012), Art. 1, pp. 248 - 275.

[http://www.politicacriminal.cl/Vol_07/n_14/Vol7N14A1.pdf]

una atenuante-, tal prohibición pierde sentido y la circunstancia aminorante debe ser considerada.

Como se puede advertir, todo lo dicho es aplicable únicamente en el caso en que se examine la procedencia de considerar en el fallo posterior circunstancias modificatorias (atenuantes o agravantes) que no podrían haberse tenido en cuenta en un eventual juzgamiento conjunto con los hechos sancionados en condenas anteriores. Existe otra posibilidad: que se analice la corrección de considerar en la sentencia posterior circunstancias que sí podrían haberse tenido en cuenta en un eventual juzgamiento conjunto, pero que no concurren en el nuevo enjuiciamiento. Esta hipótesis no es mencionada expresamente por el citado artículo 164 al aludir a las circunstancias modificatorias, pero es posible colegir de su contenido cómo debe actuarse en este caso.

En efecto, si en un juzgamiento conjunto podría haberse tenido en cuenta una determinada atenuante, pero ésta no concurriera en el enjuiciamiento posterior, según mi opinión, el tribunal, sin declararla concurrente, debería igualmente aplicar el efecto aminorante que la ley le asigna e imponer la pena correspondiente. Sólo así se evitaría el evidente perjuicio que significaría para el imputado el hecho de que no se considerara la atenuante únicamente por la decisión de otras personas, de que los hechos se juzgaran en forma separada. De lo contrario, se pasaría por alto el mandato legal de que el conjunto de penas no pueda exceder de aquella que hubiere correspondido de haberse juzgado conjuntamente los delitos. ${ }^{49}$

En la situación inversa, es decir, cuando en el juzgamiento ulterior no concurre una agravante que se podría haber tenido en cuenta si el hecho se hubiera juzgado conjuntamente con el delito anterior, dicha circunstancia no puede ser considerada. En tal evento, la decisión, no adoptada por el imputado, de juzgar en forma separada los delitos, juega en beneficio de éste.

En síntesis, tratándose de agravantes, el tribunal del fallo posterior sólo puede aplicarlas si se cumplen las exigencias copulativas de que concurran en el enjuiciamiento ulterior y que hayan podido tenerse en cuenta en un eventual juzgamiento conjunto. ${ }^{50}$ Tratándose, en cambio, de atenuantes, el tribunal puede considerarlas si concurren en el enjuiciamiento posterior, a pesar de que no se hayan podido tomar en cuenta en un juzgamiento conjunto; o bien, sin declararlas, aplicar el efecto aminorante que la ley les atribuye, cuando no concurren en el enjuiciamiento ulterior, pero sí hayan podido ser consideradas en un eventual juzgamiento conjunto.

\footnotetext{
${ }^{49}$ Véase MORALES ESPINOZA, "La regulación de la pena", cit. nota $\mathrm{n}^{\circ} 12$, p. 208, quien sin efectuar ninguna distinción entre atenuantes y agravantes (aunque menciona como ejemplo una atenuante), afirma que "para el juez posterior será posible considerar aquellas circunstancias modificatorias de responsabilidad penal que, de haberse juzgado conjuntamente los hechos, debieron tomarse en cuenta".

50 Similar, DEFENSORÍA REGIONAL METROPOLITANA NORTE. UNIDAD DE ESTUDIOS, Documento de trabajo $N^{\circ} 20$, cit. nota ${ }^{\circ} 17$, p. 7 .
} 
OLIVER, Guillermo. “Aproximación a la unificación de penas”.

\section{Examen de algunas reglas de punición de concursos de delitos que constituyen una excepción a la regla de la acumulación aritmética.}

Dado que el artículo 164 del Código Orgánico de Tribunales tiene por finalidad evitar que el imputado sufra una sanción por distintos hechos, que por ser juzgados separadamente, exceda de la que habría correspondido imponer si se hubieran juzgado en forma conjunta, porque en este caso probablemente habría procedido aplicar una regla concursal más favorable, resulta pertinente revisar sucintamente aspectos importantes de algunas reglas de esta clase.

\subsection{Reiteración de delitos de la misma especie.}

Conforme a lo que establece el artículo 351 del Código Procesal Penal,

“en los casos de reiteración de crímenes o simples delitos de una misma especie se impondrá la pena correspondiente a las diversas infracciones, estimadas como un solo delito, aumentándola en uno o dos grados" (primer inciso). En su segundo inciso, la disposición agrega que "si, por la naturaleza de las diversas infracciones, éstas no pudieren estimarse como un solo delito, el tribunal aplicará la pena señalada a aquella que, considerada aisladamente, con las circunstancias del caso, tuviere asignada una pena mayor, aumentándola en uno o dos grados, según fuere el número de los delitos". En su tercer inciso, el precepto añade que "podrá, con todo, aplicarse las penas en la forma establecida en el artículo 74 del Código Penal si, de seguirse este procedimiento, hubiere de corresponder al condenado una pena menor". Finaliza la disposición, señalando que "para los efectos de este artículo, se considerará delitos de una misma especie aquellos que afectaren al mismo bien jurídico" (inciso cuarto).

El artículo 397 del Código Procesal Penal extiende estas reglas a la reiteración de faltas de una misma especie.

Ciertamente, la explicación legal acerca de lo que se entiende por delitos de la misma especie merece una valoración positiva, ya que resulta mucho más satisfactoria que la se contenía en su antecedente, el artículo 509 del Código de Procedimiento Penal ("aquellos que estén penados en un mismo título del Código Penal o ley que los castiga"), la que era muy criticada por la doctrina, ya que conducía, por ejemplo, a estimar de la misma especie delitos tan disímiles entre sí como el homicidio y la injuria, o el aborto y la violación, y a considerar de distinta especie el infanticidio y el aborto. ${ }^{51}$ Pero, de todas formas, la previsión legal genera dudas interpretativas, muy similares a las que produce la agravante de reincidencia específica (art. $12 \mathrm{~N}^{\circ} 16 \mathrm{CP}$ ).

Es en los estudios de la parte especial del derecho penal donde se explica cuál es el bien jurídico que se ve tutelado en cada uno de los delitos, lo que ya dificulta la aplicación segura del citado artículo 351, especialmente si se considera que hay figuras delictivas respecto de las cuales no existe consenso doctrinal acerca de cuál es el bien jurídico que protegen.

\footnotetext{
${ }^{51}$ Por todos, CURY URZÚA, Derecho Penal: Parte General, cit. nota nº 43, p. 661.
} 
A ello debe añadirse el problema de determinar si es exigible o no una identidad exacta de bienes jurídicos afectados, ya que hay varios delitos que son pluriofensivos, o sea, que tutelan dos o más bienes jurídicos. En estos casos, la dificultad consiste en establecer si pueden considerarse de la misma especie dos delitos cuando el primero de ellos protege un solo bien jurídico, que también se ve tutelado, junto con otros, en el segundo; o bien, cuando se trata de dos delitos pluriofensivos que tienen en común el hecho de proteger un mismo bien jurídico, dentro de los varios que tutelan. ${ }^{52}$

Agréguese que en materia de reincidencia específica hay quienes exigen, para aplicar esta circunstancia, además de que se afecte el mismo bien jurídico, que se repita la misma forma de atentado en su contra, ${ }^{53}$ y algunos requieren, adicionalmente, que haya identidad de móviles en el autor, ${ }^{54}$ lo cual sería relevante si se quisiera extraer de la regulación de dicha agravante un criterio para la interpretación de la regla de punición de la reiteración de delitos de la misma especie.

En todo caso, frente a todas estas dudas, en principio, parece preferible una interpretación extensiva del ámbito de aplicación de la mencionada regla, ya que siempre será posible aplicar la regla general de punición del concurso material de delitos (art. $74 \mathrm{CP}$ ) si ello resulta más favorable para el imputado (art. 351 inc. $3^{\circ} \mathrm{CPP}$ ).

Cuando existe una reiteración de delitos de la misma especie, es necesario determinar si las diversas infracciones pueden ser estimadas o no como un solo delito, ya que de ello depende el camino a seguir: en caso afirmativo, se debe aplicar el inciso primero del citado artículo 351; en caso contrario, el inciso segundo. Conforme a lo que señala la doctrina mayoritaria, el criterio que se debe utilizar para aplicar esta distinción consiste en examinar si las penas de los distintos delitos se encuentran estructuradas o no sobre bases acumulables que se puedan sumar: si así fuera, como ocurre, por ejemplo, en los hurtos, las estafas y los daños, se aplicaría el inciso primero; si no fuera así, se aplicaría el inciso segundo. ${ }^{55}$

Según mi opinión, este criterio no resulta aceptable por varias razones. ${ }^{56}$ Por una parte, porque implica vulnerar el principio non bis in ídem, al considerar en dos ocasiones un mismo hecho en un sentido perjudicial para el imputado. En efecto, esta interpretación obliga, cuando se trata, por ejemplo, de varios delitos de hurto, a tomar en cuenta todas las infracciones para determinar un marco penal (al sumar las cuantías involucradas en cada uno de los delitos, inevitablemente, se está considerando la totalidad de las infracciones), y luego, nuevamente, el número de los delitos concurrentes para precisar el número de

\footnotetext{
${ }^{52}$ Se inclina por la repuesta afirmativa MATUS ACUÑA, "Proposiciones", cit. nota no 4, p. 535.

${ }^{53}$ Así, CURY URZÚA, Derecho Penal: Parte General, cit. nota no 43, p. 512.

${ }^{54}$ En este sentido, NOVOA MONREAL, Curso, cit. nota ${ }^{\circ} 5$, p. 85.

${ }^{55}$ Cfr. POLITOFF LIFSCHITZ; MATUS ACUÑA; RAMÍREZ GUZMÁN, Lecciones de derecho penal chileno: Parte general, cit. nota $n^{\circ}$ 6, p. 463. También NOVOA MONREAL, Curso, cit. nota $\mathrm{n}^{\circ}$ 5, p. 227, aunque refiriéndose al artículo 509 del Código de Procedimiento Penal.

${ }^{56}$ Por los motivos que se exponen a continuación en este trabajo, he modificado el punto de vista asumido en RODRÍGUEZ COLLAO; OLIVER CALDERÓN, "Aplicabilidad de la figura del delito continuado", cit. nota $n^{\circ} 13$, p. 260.
} 
OLIVER, Guillermo. “Aproximación a la unificación de penas”.

grados en que se aumentará la pena. ${ }^{57}$ Es cierto que la alusión al "número de los delitos" aparece explícitamente sólo en el inciso segundo del mencionado artículo 351, pero es evidente que dicho criterio para determinar el aumento de grados está implícito también en el inciso primero. ${ }^{58}$

Por otra parte, como consecuencia de lo anterior, esta interpretación conduce a una injustificable diferencia de trato para el imputado, según se aplique el primer o el segundo inciso del artículo 351. El primer inciso supondría un tratamiento mucho más severo que el segundo, ya que en éste, al tomar el legislador como base el delito que tenga asignada una pena mayor, simplemente se prescinde de las restantes infracciones, estimando el aumento de grado como suficiente compensación por este hecho. No existen motivos para sostener que la situación recogida en el primer inciso sea más grave que la contemplada en el segundo y así explicar esta diferencia. ${ }^{59}$

Además, el planteamiento que critico comporta una aplicación analógica perjudicial para el imputado, de lo prescrito en el artículo 451 del Código Penal (disposición que examino más adelante y que alude expresamente a la suma de cuantías de diversos delitos de hurto), porque lleva a la imposición de una pena mayor que la que resultaría de aplicar el inciso segundo del citado artículo $351 .^{60}$

Por último, no parece razonable tener en cuenta la forma como están establecidas las penas de las diversas infracciones para estimarlas o no como un solo delito, ya que la ley expresamente indica que para hacer esta consideración debe atenderse a "la naturaleza de las diversas infracciones" (art. 351 inc. $2^{\circ}$ CPP). Es evidente que no forma parte de la naturaleza de un delito el criterio que utiliza el legislador para sancionarlo, como por ejemplo, la cuantificación de su objeto material. ${ }^{61}$

A mi juicio, entonces, el criterio de distinción consiste, simplemente, en examinar si los varios delitos de la misma especie configuran una reiteración de un mismo delito o de delitos distintos. En el primer caso habrá que aplicar el inciso primero del artículo 351; en el segundo caso, el inciso segundo. ${ }^{62}$

\footnotetext{
${ }^{57}$ En este sentido, SOLARI PERALTA; RODRÍGUEZ COLLAO, "Determinación de la pena en los casos de reiteración de delitos", cit. nota n ${ }^{\circ}$ 9, p. 267.

${ }^{58}$ Cfr. NOVOA MONREAL, Curso, cit. nota ${ }^{\circ} 5$, p. 227, nota 9.

59 SOLARI PERALTA; RODRÍGUEZ COLLAO, "Determinación de la pena en los casos de reiteración de delitos", cit. nota n' 9, p. 266.

${ }^{60}$ Así, GARRIDO MONTT, Derecho Penal: Parte general, cit. nota n ${ }^{\circ}$ 7, p. 346, nota 687; MATUS ACUÑA, "Proposiciones", cit. nota no 4, p. 536.

${ }^{61}$ En este sentido, SOLARI PERALTA; RODRÍGUEZ COLLAO, "Determinación de la pena en los casos de reiteración de delitos", cit. nota $n^{\circ}$ 9, p. 263.

${ }^{62}$ SOLARI PERALTA; RODRÍGUEZ COLLAO, "Determinación de la pena en los casos de reiteración de delitos", cit. nota $n^{\circ}$ 9, pp. 262-264. Para estos autores, las diversas infracciones pueden estimarse como un solo delito (y aplicárseles, en consecuencia, el primer inciso del artículo 351) cuando sean de la misma naturaleza (para determinar lo cual debería atenderse a las descripciones típicas, concretamente, a la acción, las circunstancias y modos de ejecución recogidos en los tipos) y tengan, además, la misma pena.
} 
Polít. crim. Vol. 7, No 14 (Diciembre 2012), Art. 1, pp. 248 - 275.

[http://www.politicacriminal.cl/Vol_07/n_14/Vol7N14A1.pdf]

En otro orden de ideas, puede suscitarse el problema de determinar en qué momento deben considerarse las circunstancias modificatorias concurrentes. En el segundo inciso del artículo 351 la ley expresamente resuelve el punto, pues ordena tomar en cuenta "las circunstancias del caso" antes de efectuar el aumento de grados de pena. En el primer inciso, en cambio, la ley nada dice. No obstante, según mi opinión, no puede efectuarse aquí una argumentación a contrario sensu, sino que lo que se indica en el inciso segundo también debe observarse en el primero, en aras de una interpretación armónica del precepto. $^{63}$ Carecería de sentido que en un caso (inciso primero) las circunstancias modificatorias se consideraran después de efectuado el aumento de pena y en el otro (inciso segundo), antes de dicho aumento. Por lo demás, la necesidad de comparar la pena a que conduce el citado artículo 351 con la que se impondría conforme al artículo 74 del Código Penal, para determinar cuál resulta más favorable para el imputado, parece abonar la tesis que defiendo, ya que si en el inciso primero el aumento se hiciera a partir del marco penal del correspondiente tipo, se estaría comparando una pena abstracta (art. 351 inc. $1^{\circ}$ $\mathrm{CPP})$ con una concreta (art. $74 \mathrm{CP}){ }^{64}$

Finalmente, un sector de la doctrina sostiene que al efectuarse la mencionada comparación penológica para determinar cuál sanción resulta más benigna para el imputado, debería atenderse sólo a consideraciones cuantitativas (no cualitativas), ya que el artículo 351 del Código Procesal Penal utiliza para ello la expresión "pena menor" (inc. $3^{\circ}$ ). ${ }^{65}$ A mi juicio, sin embargo, es perfectamente posible realizar una comparación no sólo cuantitativa acerca de la duración temporal de las penas posibles de imponer, sino también cualitativa en relación con su gravedad, en la determinación de cuál es más favorable. En otras palabras, estimo procedente efectuar las consideraciones que la teoría de la sucesión de leyes penales suele hacer para desentrañar cuál ley (la vigente al tiempo del hecho o la que entra en vigor con posterioridad) es más benigna. Desde un punto de vista teleológico, una comparación cualitativa de las penas (que acompañe a una cuantitativa) no puede entenderse excluida, porque esto implicaría la posibilidad de imponer sanciones de gravedad considerable (aunque de duración acotada) que constituyan una intervención penal excesiva para la entidad y el número de los delitos cometidos. Precisamente para evitar esto se creó la regla de punición de la reiteración de delitos de la misma especie. Además, el argumento literal que esgrime la tesis que critico no parece de recibo, ya que conforme al Diccionario de la Lengua de la Real Academia Española, la voz "menor" quiere decir, en su primera acepción, "inferior a otra cosa en cantidad, intensidad o calidad", ${ }^{66}$ significado que coincide con el sentido natural y obvio del término, según su uso general. Esto demuestra que el campo semántico de dicho vocablo no sólo permite utilizar consideraciones cuantitativas, sino también cualitativas.

\footnotetext{
${ }^{63}$ SOLARI PERALTA; RODRÍGUEZ COLLAO, "Determinación de la pena en los casos de reiteración de delitos", cit. nota ${ }^{\circ}$ 9, p. 265.

${ }^{64}$ En este sentido, MATUS ACUÑA, "Proposiciones", cit. nota n ${ }^{\circ} 4$, p. 537, nota 33.

${ }^{65}$ MATUS ACUÑA, "Proposiciones", cit. nota n' 4, p. 538.

${ }^{66}$ El destacado en cursiva es mío.
} 
OLIVER, Guillermo. "Aproximación a la unificación de penas".

\subsection{Reiteración de hurtos.}

En materia de concursos, existe una norma que, a pesar de estar ubicada dentro del Párrafo 5 del Título IX del Libro II del Código Penal, que contiene disposiciones comunes al hurto, al robo y al abigeato, regula una situación aplicable sólo al delito de hurto. Se trata del artículo 451, conforme al cual

"en los casos de reiteración de hurtos, aunque se trate de faltas, a una misma persona, o a distintas personas en una misma casa, establecimiento de comercio, centro comercial, feria, recinto o lugar el tribunal calificará el ilícito y hará la regulación de la pena tomando por base el importe total de los objetos sustraídos, y la impondrá al delincuente en su grado superior". Su inciso segundo agrega que "esta regla es sin perjuicio de lo dispuesto en el artículo 447".

Esta disposición consagra una excepción a la regla general de punición del concurso material de delitos (art. $74 \mathrm{CP}$ ), y más concretamente, a la regla de castigo de la reiteración de delitos de la misma especie (arts. 351 y 397 CPP).

Antiguamente, se creía que había aquí una manifestación de la figura del delito continuado $^{67}$. Sin embargo, actualmente se sostiene, con razón, que no se trata de un único delito (continuado), sino de varios. ${ }^{68}$ La propia disposición emplea la expresión "reiteración", lo que supone una pluralidad delictiva. ${ }^{69}$ No es entonces un delito continuado tratado con severidad (la consecuencia de considerar que el delito continuado es uno solo, es la de aplicarle la pena correspondiente al hecho único cometido; ${ }^{70}$ el artículo $451 \mathrm{CP}$, en cambio, contempla una agravación), sino un concurso material de delitos tratado con benignidad, probablemente por la estrecha conexión que existe entre las diversas acciones, lo que hace que se parezca a un delito continuado. ${ }^{71} \mathrm{Si}$ tiene lugar un delito continuado de hurto, no se aplica esta disposición, sino el artículo $446 \mathrm{CP}$.

A pesar de que se conoce esta regla con el nombre de reiteración de hurtos, para que se aplique no basta con que se demuestre que ha habido un concurso material de hurtos, sino que se requiere además que se acredite que los diversos delitos se han cometido contra una misma persona, cualesquiera hayan sido sus lugares de ejecución, o contra distintas

\footnotetext{
${ }^{67}$ Así, FONTECILlA RIQUELME, Rafael, Concursos de delincuentes, de delitos y de leyes penales y sus principales problemas jurídicos, Santiago: Editorial Jurídica de Chile, 1956, p. 70; PICA URRUTIA, René, Reglas para la aplicación de las penas, $4^{a}$ ed., Santiago: Editorial Jurídica de Chile, 1992, p. 223; DEL RÍO, Raimundo, Derecho Penal, t. III, Santiago: Nascimento, 1935, p. 456; LABATUT GLENA, Gustavo, Derecho Penal, t. II, $7^{a}$ ed., actualizada por Julio Zenteno Vargas, Santiago: Editorial Jurídica de Chile, 2000 , p. 215.

${ }^{68}$ GARRIDO MONTT, Mario Derecho Penal: Parte Especial, t. IV, $4^{a}$ ed., Santiago: Editorial Jurídica de Chile, 2008, p. 269.

${ }^{69}$ Ya se pronunciaban en este sentido, CURY URZÚA, Enrique, "El delito continuado", Revista de Ciencias Penales, t. XVIII (1959), pp. 201-215, p. 208; NOVOA MONREAL, Eduardo, "El delito continuado en Chile: un fetiche jurídico", Revista de Ciencias Penales, t. XXIII (1964), pp. 139-153, p. 148.

${ }^{70}$ Cfr. POLITOFF LIFSCHITZ; MATUS ACUÑA; RAMÍREZ GUZMÁN, Lecciones de derecho penal chileno: Parte general, cit. nota $\mathrm{n}^{\circ}$ 6, p. 449.

${ }^{71}$ ETCHEBERRY, Alfredo, Derecho Penal: Parte General, t. II, $3^{a}$ ed., Santiago: Editorial Jurídica de Chile, 1998, pp. 113 y ss.
} 
Polít. crim. Vol. 7, No 14 (Diciembre 2012), Art. 1, pp. 248 - 275.

[http://www.politicacriminal.cl/Vol_07/n_14/Vol7N14A1.pdf]

personas en un mismo lugar. En el delito de robo con fuerza en las cosas, a la voz "lugar" suele darse un sentido preciso: un espacio delimitado y cerrado. En materia de hurto, en cambio, no existen razones para dar a este vocablo un alcance tan restringido, por lo que puede entenderse como cualquier espacio, se encuentre delimitado y cerrado o no. ${ }^{72}$ Lo más frecuente será que los diversos delitos se cometan en espacios delimitados y cerrados, pero puede que no sea así. De hecho, la propia disposición menciona la voz "feria", la que como es sabido, muchas veces no ocupa un espacio cerrado.

Por otra parte, la agravación que la regla contempla, dados los términos utilizados por el legislador para establecerla, resulta aplicable en pocos casos. Ello es así, porque tras ordenar que para determinar la sanción se tome por base el importe total de los objetos sustraídos, la disposición obliga a imponer la pena correspondiente "en su grado superior". Como se comprenderá, para que esto último pueda hacerse, es necesario que el marco penal que corresponda a la sumatoria del valor de las cosas hurtadas, sea compuesto por dos o más grados. ${ }^{73}$ De los cinco marcos de pena que existen para el hurto, sólo dos cumplen este requisito: el previsto en el artículo $446 \mathrm{~N}^{\circ} 1 \mathrm{CP}$ (presidio menor en sus grados medio a máximo), que será aplicable cuando la suma de los valores exceda de cuarenta (y no pase de cuatrocientas) unidades tributarias mensuales, y el contemplado en el artículo 494 bis CP (prisión en su grado mínimo a medio), que será aplicable cuando dicha sumatoria no exceda de media unidad tributaria mensual. En los restantes casos, esto es, cuando la suma total excede de media unidad tributaria mensual y no pasa de cuatro unidades tributarias mensuales (art. $446 \mathrm{~N}^{\circ} 3 \mathrm{CP}$ ), o si excede de cuatro y no pasa de cuarenta unidades tributarias mensuales (art. $446 \mathrm{~N}^{\circ} 2 \mathrm{CP}$ ), o si excede de cuatrocientas unidades tributarias mensuales (art. 446 inc. final CP), la agravación no resulta aplicable, con lo que la pena a imponer será idéntica a la que correspondería si se tratara de un delito continuado. $^{74}$

\section{Aspectos procesales envueltos en la "unificación" de penas.}

\subsection{Tribunal competente.}

Tal como lo dije más arriba, ${ }^{75}$ la sustitución de la expresión "la última sentencia", que se contenía en el proyecto de la Ley $\mathrm{N}^{\circ} 19.665$, por la de "fallo posterior", se hizo con la finalidad de abarcar los casos de sentencias condenatorias sucesivas dictadas en contra de un mismo imputado. De ello se desprende que las solicitudes de regulación de pena conforme al artículo 164 del Código Orgánico de Tribunales, pueden dirigirse en forma sucesiva a cada uno de los tribunales que dicten un nuevo fallo condenatorio contra el imputado, a medida que los vayan dictando, y a su vez, que cada uno de ellos, de oficio,

\footnotetext{
${ }^{72}$ En contra, POLITOFF LIFSCHITZ, Sergio; MATUS ACUÑA, Jean Pierre; RAMíREZ GuZMÁN, María Cecilia, Lecciones de derecho penal chileno: Parte especial, $2^{a}$ ed., Santiago: Editorial Jurídica de Chile, 2005 , p. 313.

${ }^{73}$ GARRIDO MONTT, Derecho Penal. Parte Especial, cit. nota $n^{\circ}$ 68, p. 269; ETCHEBERRY, Alfredo, Derecho Penal: Parte Especial, t. III, $3^{a}$ ed., Santiago: Editorial Jurídica de Chile, 1998, p. 362.

${ }^{74}$ POLITOFF LIFSCHITZ; MATUS ACUÑA; RAMÍREZ GUZMÁN, Lecciones de derecho penal chileno: Parte especial, cit. nota $\mathrm{n}^{\circ} 72$, p. 312.

${ }^{75}$ Véase nota $\mathrm{n}^{\circ} 24$.
} 
OLIVER, Guillermo. “Aproximación a la unificación de penas”.

debe adecuar la pena que impone a la regla que dicho precepto establece. ${ }^{76}$ Es indiferente, para estos efectos, la jerarquía del tribunal que dicte la sentencia condenatoria posterior. Puede tratarse de un Juzgado de Garantía, de un Tribunal de Juicio Oral en lo Penal, de una Corte de Apelaciones, o incluso, de la Corte Suprema.

Fluye de lo expresado que no corresponde pedir la adecuación de pena que prevé el citado artículo 164 a un Juzgado de Garantía que no ha dictado el fallo posterior, a pesar de que este tribunal sea el competente para conocer y resolver solicitudes y reclamos relativos a la ejecución de las sanciones penales (art. 14 inc. $2^{\circ}$ letra $\mathrm{f} \mathrm{COT}$ ). Constátese que se trata de una cuestión que concierne a la determinación de la pena y no a su ejecución. ${ }^{77}$

\subsection{Oportunidad.}

Aun cuando la ley no ha señalado cuál es el momento en que resulta procedente solicitar la aplicación del artículo 164 del Código Orgánico de Tribunales, parece razonable entender que ello es posible en dos ocasiones. La primera posibilidad es pedirlo en la audiencia de determinación de pena a que alude el artículo 343 inciso $4^{\circ}$ del Código Procesal Penal, ya que la existencia de condenas anteriores por otros hechos que pudieron haber sido juzgados conjuntamente con el que es objeto del juicio posterior, es un factor relevante para la determinación de la nueva pena a imponer. ${ }^{78}$ Esto es válido no sólo en el juicio oral del procedimiento ordinario, sino también en el del procedimiento simplificado y en el del procedimiento por delito de acción privada, e incluso en el procedimiento abreviado, atendida la remisión que en cada uno de estos procedimientos la ley hace al procedimiento ordinario (arts. 389, 405 y 415 CPP, respectivamente). En el caso del procedimiento simplificado con admisión de responsabilidad, es pertinente el artículo 395 inciso $2^{\circ}$ del mismo Código, al aludir expresamente a la posibilidad de incorporar antecedentes que sirvan para la determinación de la pena. ${ }^{79}$

La otra posibilidad consiste en pedir al tribunal que ya dictó el fallo condenatorio posterior, que cite a los intervinientes a una audiencia especial para solicitar en ella la aplicación del citado artículo 164. De hecho, el inciso segundo de esta disposición parece hacer referencia, precisamente, a esta hipótesis. ${ }^{80}$ Incluso, una argumentación analógica, a partir de lo establecido en el artículo 18 del Código Penal, avala esta tesis. Conforme a este precepto, si después de una sentencia condenatoria firme se promulga una ley que exime el hecho de toda pena o le aplica una menos rigurosa, el tribunal que la dictó debe modificarla, de oficio o a petición de parte, para ajustarla a la nueva ley. Pues bien, si la modificación de un fallo condenatorio resulta procedente por una causa sobreviniente a su dictación (nueva ley más favorable), con mayor razón lo es cuando la causa es preexistente (posibilidad de juzgamiento conjunto de los hechos). ${ }^{81}$ Máxime, si se observa que el

\footnotetext{
${ }^{76}$ MORALES ESPINOZA, "La regulación de la pena”, cit. nota n 12, p. 209; DEFENSORÍA REGIONAL METROPOLITANA NORTE. UNIDAD DE ESTUDIOS, Documento de trabajo $N^{o} 20$, cit. nota $n^{\circ} 17$, p. 9 .

${ }^{77}$ MORALES ESPINOZA, "La regulación de la pena", cit. nota n 12, p. 209.

${ }^{78}$ MORALES ESPINOZA, "La regulación de la pena", cit. nota no 12, pp. 209 y ss.

${ }^{79}$ SÁNCHEZ PIAZZA, La regla de determinación de la pena, cit. nota $\mathrm{n}^{\circ} 22$, pp. 51 y ss.

${ }^{80}$ MORALES ESPINOZA, "La regulación de la pena", cit. nota $n^{\circ} 12$, p. 210.

${ }^{81}$ Véase SÁNCHEZ PIAZZA, La regla de determinación de la pena, cit. nota $\mathrm{n}^{\circ}$ 22, p. 52, nota 148.
} 
Polít. crim. Vol. 7, No 14 (Diciembre 2012), Art. 1, pp. 248 - 275.

[http://www.politicacriminal.cl/Vol_07/n_14/Vol7N14A1.pdf]

fundamento de la retroactividad penal in bonam partem es similar al de la llamada "unificación" de penas: evitar la aplicación de sanciones innecesarias o desproporcionadas. $^{82}$

\subsection{Recursos.}

Tampoco ha señalado la ley cuál es el medio de impugnación que corresponde utilizar cuando no se ha aplicado el artículo 164 del Código Orgánico de Tribunales, debiendo habérselo aplicado, cuando se lo ha aplicado en circunstancias de que no correspondía hacerlo, o cuando procedía aplicarlo, pero se lo ha hecho de manera incorrecta, por lo que en cualquiera de estos casos habrá que acudir a las reglas generales.

En la primera de las posibilidades expuestas más arriba acerca de la oportunidad para solicitar la aplicación del citado artículo 164, la cuestión relativa a los recursos procesales es fácil de abordar. Cuando la petición se formula en la audiencia de determinación de pena o en el momento que señala el artículo 395 inciso $2^{\circ}$ del Código Procesal Penal, la decisión que la concede o deniega se inserta en la sentencia definitiva, por lo que la forma de impugnarla es la misma que existe para recurrir contra ésta: ${ }^{83}$ en el juicio oral, en el procedimiento simplificado y en el procedimiento por delito de acción privada, el recurso de nulidad; en el procedimiento abreviado, el recurso de apelación. ${ }^{84}$

En cambio, cuando la solicitud se ha hecho en una audiencia especial posterior a la sentencia condenatoria, el problema de determinar los recursos procesales pertinentes no es tan sencillo de resolver. Si la petición se ha efectuado ante un Juzgado de Garantía, resultaría procedente interponer un recurso de apelación, argumentando que la resolución que acoge o rechaza aquélla pone término al procedimiento especial de adecuación de la sentencia definitiva a lo dispuesto en el citado artículo 164, o sea, a lo que en la práctica se denomina "audiencia de 'unificación' de penas". De este modo, se cumpliría la exigencia del artículo 370 letra a) del Código Procesal Penal para la apelación.

Pero cuando la solicitud se ha hecho ante un Tribunal de Juicio Oral en lo Penal, no cabría apelación (art. 364 CPP). Únicamente, sería procedente la interposición de un recurso de queja, considerando que la resolución que acoge o rechaza la petición no es susceptible de recurso alguno, ordinario o extraordinario (art. 545 COT). No obstante, es muy dudoso que esta resolución pueda ser considerada como sentencia definitiva o como sentencia

\footnotetext{
${ }^{82}$ Cfr. OLIVER CALDERÓN, Guillermo, Retroactividad e irretroactividad de las leyes penales, Santiago: Editorial Jurídica de Chile, 2007, pp. 259-323.

${ }^{83}$ DEFENSORÍA REGIONAL METROPOLITANA NORTE. UNIDAD DE ESTUDIOS, Documento de trabajo $\mathrm{N}^{\mathrm{o}} 20$, cit. nota $\mathrm{n}^{\mathrm{o}} 17$, p. 10 , aunque aludiendo solamente al recurso de nulidad por errónea aplicación del derecho.

${ }^{84}$ No menciono el procedimiento monitorio, porque en éste no hay audiencias, y además, porque si de cualquier forma el imputado, dentro de los quince días siguientes a la notificación de la resolución que impone la multa, manifiesta su disconformidad con su monto, por superar la suma de éste con el de las multas impuestas en condenas anteriores, al monto total que se podría haber impuesto por hechos que podrían haber sido juzgados conjuntamente con el hecho nuevo, la tramitación continúa conforme a las reglas del procedimiento simplificado. Similar, SÁNCHEZ PIAZZA, La regla de determinación de la pena, cit. nota $\mathrm{n}^{\circ}$ 22, p. 58 , nota 167.
} 
OLIVER, Guillermo. “Aproximación a la unificación de penas”.

interlocutoria que ponga fin al juicio o haga imposible su continuación -requisito de admisibilidad de todo recurso de queja-, toda vez que el juicio ya habrá terminado, precisamente, por sentencia definitiva. Así las cosas, sólo restaría ejercer una acción constitucional de amparo ${ }^{85}$-siempre que la resolución, por no aplicar el artículo 164 del Código Orgánico de Tribunales o por hacerlo mal, produjera una afectación indebida del derecho del imputado a la libertad personal y la seguridad individual-, argumentando que se estaría atentando contra su libertad, con infracción de lo dispuesto en la ley (el citado artículo 164) o en la Constitución. En este último caso, habría que estimar infringido el artículo $19 \mathrm{~N}^{\circ} 7$ letra b) de la Carta Fundamental, según el cual "nadie puede ser privado de su libertad personal ni ésta restringida sino en los casos y en la forma determinados por la Constitución y las leyes". Además, habría que considerar vulnerada la prohibición de exceso, la que al igual que lo que sucede en muchas Constituciones del mundo, no posee un reconocimiento explícito en la Constitución chilena, lo que no impide estimarla implícitamente consagrada en la regulación del principio de subsidiariedad (art. $1^{\circ}$ inc. $3^{\circ}$ ) y en la garantía de intangibilidad del contenido esencial de los derechos fundamentales (art. $\left.19 \mathrm{~N}^{\circ} 26\right){ }^{86}$

En todo caso, cualquiera sea el recurso que se estime procedente contra la resolución que acoge o rechaza la solicitud de adecuación de la pena conforme al artículo 164 del Código Orgánico de Tribunales, parece claro que no puede interponerlo la víctima si no ha deducido querella, a pesar de que haya intervenido en el procedimiento, ya que el artículo 109 letra f) del Código Procesal Penal sólo le reconoce el derecho de impugnar el sobreseimiento o la sentencia absolutoria; el citado artículo 164 únicamente es aplicable cuando se dicta sentencia condenatoria. ${ }^{87}$

\footnotetext{
${ }^{85}$ En este sentido, MORALES ESPINOZA, "La regulación de la pena", cit. nota no 12, p. 213; DEFENSORÍA REGIONAL METROPOLITANA NORTE. UNIDAD DE ESTUDIOS, Documento de trabajo $\mathrm{N}^{\mathrm{o}} 20$, cit. nota $\mathrm{n}^{\mathrm{o}} 17$, p. 10.

${ }^{86}$ Cfr. BASCUÑÁN RODRÍGUEZ, Antonio, "Delitos contra intereses instrumentales", Revista de Derecho de la Universidad Adolfo Ibáñez, $\mathrm{n}^{\circ} 1$ (2004), pp. 291-345, pp. 323 y ss.

${ }^{87}$ Así, SÁNCHEZ PIAZZA, La regla de determinación de la pena, cit. nota $\mathrm{n}^{\circ} 22$, pp. 58 y ss.
} 
Polít. crim. Vol. 7, No 14 (Diciembre 2012), Art. 1, pp. 248 - 275.

[http://www.politicacriminal.cl/Vol_07/n_14/Vol7N14A1.pdf]

\section{BIBLIOGRAFÍA CITADA}

BASCUÑÁN RODRÍGUEZ, Antonio, "Delitos contra intereses instrumentales", Revista de Derecho de la Universidad Adolfo Ibáñez n 1, (2004), pp. 291-345.

CERDA SAN MARTÍN, Rodrigo, "La unificación de penas contemplada en el artículo 164 del Código Orgánico de Tribunales", Revista de Justicia Penal n 2 (2008), pp. 187- 208.

CORREA BRAVO, Agustín, "Ochenta y cuatro años de presidio", Revista Forense Chilena, t. IV (1888), pp. 508-511.

CURY URZÚA, Enrique, "El delito continuado", Revista de Ciencias Penales, t. XVIII (1959), pp. 201-215.

, Derecho Penal: Parte General, $9^{a}$ ed., Santiago: Ed. Universidad Católica de Chile, 2009.

DEFENSORÍA REGIONAL METROPOLITANA NORTE, Documento de trabajo $\mathrm{n}^{\circ} 20$ : "Acumulación o unificación de penas", Santiago: 2007, diciembre.

DEL RÍO, Raimundo, Derecho Penal, t. III, Santiago: Ed. Nascimento, 1935.

DÍAZ CRUZAT, Andrés, "Esquema sobre la unificación de penas de la ley no 19.366", Gaceta Jurídica, n 236 (2000), pp. 147-152.

Jurídica $\mathrm{n}^{\circ} 245$ (2000), pp. 7-9.

ETCHEBERRY, Alfredo, Derecho Penal: Parte General, t. II, $3^{a}$ ed., Santiago: Ed. Jurídica de Chile, 1998.

Jurídica de Chile, 1998.

FELIÚ, Daniel, "De la acumulación de los delitos según nuestro Código Penal", Revista Forense Chilena, t. VI (1890), pp. 436-444.

FONTECILLA RIQUELME, Rafael, Concursos de delincuentes, de delitos y de leyes penales y sus principales problemas jurídicos, Santiago: Editorial Jurídica de Chile, 1956.

GARRIDO MONTT, Mario, Derecho Penal: Parte General, t. II, $2^{a}$ ed., Santiago: Editorial Jurídica de Chile, 2001.

, Derecho Penal: Parte Especial, t. IV, $4^{a}$ ed., Santiago:

Editorial Jurídica de Chile, 2008.

GUZMÁN DALBORA, José Luis, "El abono de las medidas cautelares a la pena", Revista Procesal Penal $\mathrm{n}^{\circ} 72$ (2008), pp. 9-20.

HERNÁNDEZ BASUALTO, Héctor, "Abono de prisión preventiva en causa diversa", Informes en Derecho: Doctrina Procesal Penal 2009, $\mathrm{n}^{\mathrm{o}} 7$ (2010, octubre), pp. 109120.

HORVITZ LENNON, María Inés; LÓPEZ MASLE, Julián, Derecho Procesal Penal Chileno, t. I, Santiago: Editorial Jurídica de Chile, 2006.

LABATUT GLENA, Gustavo, Derecho Penal, t. II, $7^{a}$ ed. actualizada por Julio Zenteno Vargas, Santiago: Editorial Jurídica de Chile, 2000.

LATORRE, Enrique et al., "Ciento veintitrés años cuarenta y un días de presidio", Revista Forense Chilena, t. XIII (1899), pp. 399-402.

LÓPEZ L., Osvaldo, Derecho Procesal Penal Chileno, $2^{a}$ ed., Santiago: Ediar Editores, 1983. 
OLIVER, Guillermo. “Aproximación a la unificación de penas”.

MATUS ACUÑA, Jean Pierre, "Proposiciones respecto de las cuestiones no resueltas por la ley $\mathrm{n}^{\mathrm{o}} 20.084$ en materia de acumulación y orden de cumplimiento de las penas", Ius et Praxis $\mathrm{n}^{\circ} 2$ (2008), pp. 525-559.

, "Comentario a la SCA de Temuco de 1 de diciembre de 2008. Rol 1100/2008”, Doctrina y jurisprudencia penal, Revista de Derecho de la Universidad de Los Andes. El engaño y el error en la estafa, $\mathrm{n}^{\circ} 1$ (2010), pp. 115125.

MENDAÑA, Ricardo Jorge, "Unificación de penas”, Revista Jurídica Argentina La Ley, C (1978), pp. 720-728.

MORALES ESPINOZA, Eduardo, "La regulación de la pena en conformidad con el artículo 164 del Código Orgánico de Tribunales", Revista de Estudios de la Justicia $\mathrm{n}^{\circ} 14$ (2011), pp. 199-216.

NOVOA MONREAL, Eduardo, "El delito continuado en Chile: un fetiche jurídico", Revista de Ciencias Penales, t. XXIII (1964), pp. 139-153. , Curso de Derecho Penal Chileno, t. II, $3^{a}$ ed., Santiago: Editorial Jurídica de Chile, 2005.

OLIVER CALDERÓN, Guillermo, Retroactividad e irretroactividad de las leyes penales, Santiago: Editorial Jurídica de Chile, 2007.

PICA URRUTIA, René, Reglas para la aplicación de las penas, $4^{a}$ ed., Santiago: Editorial Jurídica de Chile, 1992.

PFEFFER URQUIAGA, Emilio, Código Procesal Penal anotado y concordado, $2^{a}$ ed., Santiago: Editorial Jurídica de Chile, 2006.

POLITOFF LIFSCHITZ, Sergio; MATUS ACUÑA, Jean Pierre; RAMÍREZ GUZMÁN, María Cecilia, Lecciones de derecho penal chileno: Parte general, $2^{a}$ ed., Santiago: Editorial Jurídica de Chile, 2004.

Lecciones de derecho penal chileno: Parte especial, $2^{a}$ ed., Santiago: Editorial Jurídica de Chile, 2005.

RODRÍGUEZ COLLAO, LUIS; OLIVER CALDERÓN, Guillermo, “Aplicabilidad de la figura del delito continuado en los delitos sexuales. Comentario a un fallo", Revista de Derecho, Universidad Católica del Norte, $\mathrm{n}^{\circ}$ 1, año 16 (2009), pp. 251-264.

SÁNCHEZ PIAZZA, José Manuel, La regla de determinación de la pena contemplada en el artículo 164 del Código Orgánico de Tribunales, Valparaíso: Tesis Pontificia Universidad Católica de Valparaíso, 2012.

SOLARI PERALTA, Tito; RODRÍGUEZ COLLAO, Luis, "Determinación de la pena en los casos de reiteración de delitos (Ámbito de aplicación del Artículo 509 del Código de Procedimiento Penal)", Revista de Derecho, Pontificia Universidad Católica de Valparaíso, vol. III (1979), pp. 255-271.

VAN WEEZEL, Alex, "Unificación de las penas: La regla del artículo 160 inciso $2^{\circ}$ del Código Orgánico de Tribunales", Revista de Derecho de la Universidad de Concepción $\mathrm{n}^{\circ}$ 207, año LXVIII (2000), pp. 55-58.

ZAFFARONI, Eugenio Raúl; ALAGIA, Alejandro; SLOKAR, Alejandro, Derecho Penal: Parte General, $2^{a}$ ed., Buenos Aires: Ediar, 2003. 